\title{
AN EXPLORATION OF BLACK COLLEGE MEN'S PERSPECTIVE ON THEIR CAREER OUTLOOK THROUGH CLUSTER ANALYSIS
}

\author{
A Dissertation presented to \\ the Faculty of the Graduate School \\ at the University of Missouri-Columbia
}

In Partial Fulfillment

of the Requirements for the degree

Doctor of Philosophy

by

JASON EDWARDS

Dr. Patrick Rottinghaus, Dissertation Supervisor

Department of Educational, School, and Counseling Psychology

July 2021 
The undersigned, appointed by the Dean of the Graduate School, have examined the dissertation entitled

\section{AN EXPLORATION OF BLACK COLLEGE MEN'S PERSPECTIVES ON THEIR CAREER OUTLOOK THROUGH CLUSTER ANALYIS}

presented by Jason Edwards,

a candidate for the degree of doctor of philosophy, and hereby certify that, in their opinion, it is worthy of acceptance.

Professor Patrick J. Rottinghaus

Professor Lisa Y. Flores

Professor Matthew P. Martens

Professor Lagarrett J. King 


\section{ACKNOWLEDGEMENTS}

I would like to express my deepest gratitude to my committee chair Dr. Patrick Rottinghaus. Thank you for supporting me and being a consistent positive force to help me complete this project. Thank you to my committee members Dr. Lisa Florez, Dr. Matthew Martens, and Dr. Lagarrett King. Each of you has been instrumental in assisting me on my journey.

I would also like to thank my family as they have made sacrifices during this time to create space for me to work on my dissertation. My mother has been especially supportive as she was able to draw on her own doctorate experiences to support me. Thank you Steffanie as you have always been there for me, and I appreciated how you kept me thinking positive about moving forward. I want to thank my father who is no longer with us. The memory of his presence and the sacrifices he made for me and my family our always present in my heart. Thank you, Salim, for being my biggest cheerleader during the most challenging times. Thank you, Dr. James Scott, for giving me the guidance and truth I needed to hear. I know you and Aunt Ophelia are always in my corner.

I want to thank my peers in the program Dr. Reuben Faloughi, Dr. Danielle Orosco, Bini Sebastion, Johanna Milord as they were all big supporters along the way. I also want to thank Dr. Marjorie Dorime-Williams because she was a both a huge academic and emotional support as I pushed to complete the dissertation. I want to also acknowledge my friends who have always been there to listen along the way: Quinton, Moyenda, Levi, Vince, George, Lionel, Khalid, Brian, Chuck, and Chris. I want to give a special thanks to Kevin whose support came at a key time in this process. 


\section{TABLE OF CONTENTS}

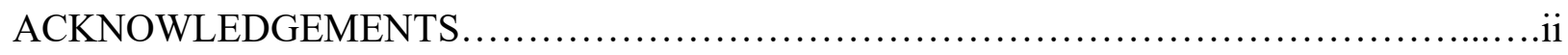

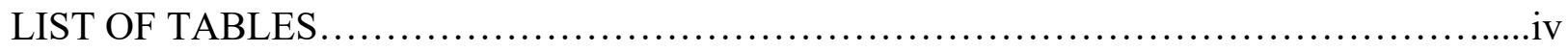

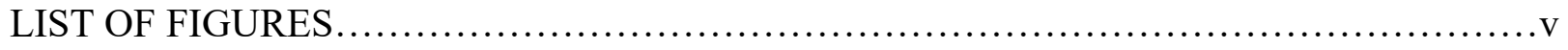

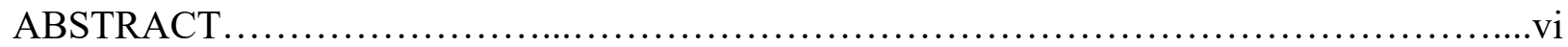

CHAPTERS

CHAPTER 1: INTRODUCTION...............................................

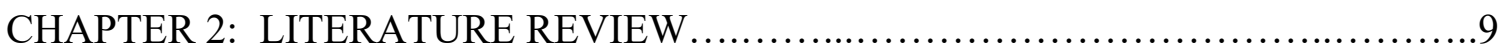

Career Adaptability................................................ 10

Career Decision Making Self-Efficacy....................................14

Career Optimism.......................................................... 16

Impostor Phenomenon............................................. 18

Racial Identity.................................................... 19

Need For Present Study............................................25

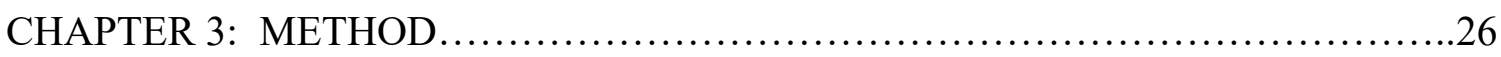

CHAPTER 4: RESULTS................................................. 36

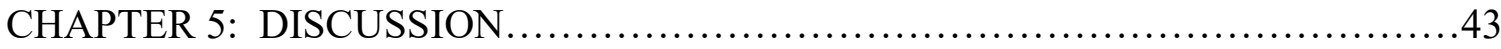

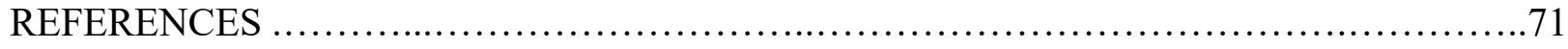

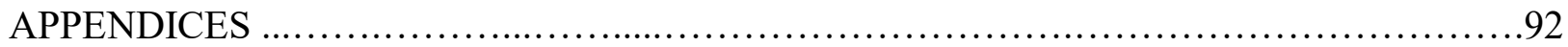

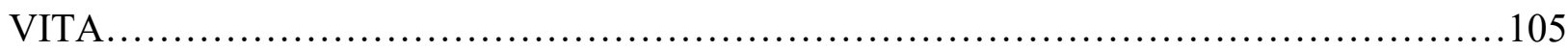




\section{LIST OF TABLES}

TABLE

PAGE

Table 1 - Bivariate Correlations, Reliability Estimates, Means, and Standard

Deviations..............................................................59

Table 2 - MIBI Subscale Means.................................................60

Table 3 - Final Six-Cluster Mean Centers............................................61

Table 4 - Cluster Sizes and Labels for the Six-Cluster Solution ...........................62

Table 5 - Cluster Comparisons.................................................63

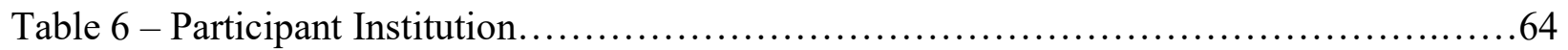




\section{LIST OF FIGURES}

$\underline{\text { FIGURE }}$

$\underline{\text { PAGE }}$

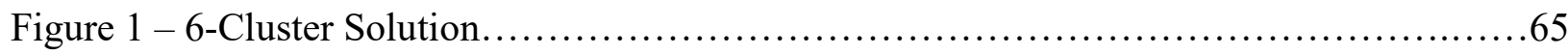

Figure $2-7$-Cluster Solution...................................................66

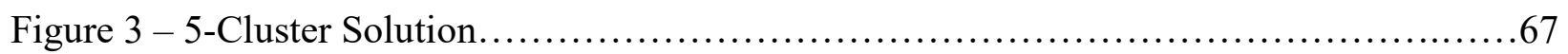

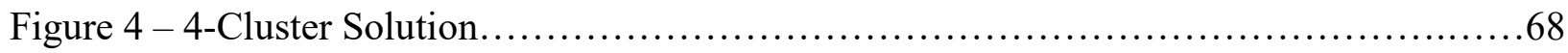

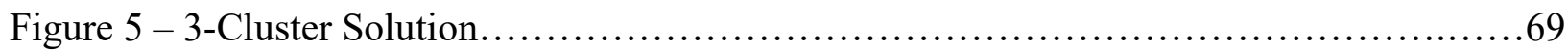

Figure 6 - 2-Cluster Solution................................................ 70

Figure 7 - Participants by Region of the United States.................................. 71 


\title{
AN ABSTRACT OF THE DISSERTATION OF
}

Jason Edwards, for the Doctor of Philosophy degree in counseling psychology, at University of Missouri-Columbia.

\section{TITLE: AN EXPLORATION OF BLACK COLLEGE MEN'S PERSPECTIVE ON THEIR CAREER OUTLOOK THROUGH CLUSTER ANALYSIS}

MAJOR PROFESSOR: Dr. Patrick J. Rottinghaus

\begin{abstract}
Black men currently significantly lag other groups in their participation in high status occupations. There have been several studies to highlight the challenges of Black people in the workplace but there is a lack of research that assess how college men think about their career futures (Barrett, 2004; Byars-Winston, 2010; Hoffman, Llagas, \& Snyder, 2003). The current study aims to explore what Black college men believe about their career potential postgraduation during a critical time in the development of their careers. The constructs career adaptability, career decision self-efficacy, career optimism, and the impostor phenomenon will be used to identify strengths and internal barriers that both positively and negatively influence the psychology of Black men in relation to their career motivations, aspirations, and their confidence in their ability to successfully navigate the career landscape. Cluster analysis was used to identify groups of participants based upon the constructs measured and demographic variables. A six-cluster solution was identified in the sample that represented distinct profiles of career readiness. The clusters were labeled "Impostor with low optimism and career agency", "Highly prepared impostor", "Comfortable", "Not prepared", "Very comfortable and highly prepared", "Impostor". Black Racial Identity measures suggest that positive esteem held for Black people corelates with high career preparedness and lower distress. The results from this
\end{abstract}


study provides information useful for vocational practitioners and university administrators who support the career development needs of Black college men.

Keywords: Black College Men, Academic Self-Concept, Career Adaptability, Career Decision Self-efficacy, Career Optimism, Impostor Phenomenon 


\section{CHAPTER 1}

\section{INTRODUCTION}

There is a significant wealth gap between Black people and the majority White populations in the United States. While Black people have made substantial strides in improved lifestyles following slavery, the Jim Crow era, and the civil rights struggle, they still lag significantly behind Caucasians in several economic indicators including income, household wealth, home ownership, and business ownership. Some of the barriers to wealth equality were removed due to legislation that emerged from the civil rights movement. In 1954 the U. S. Supreme Court ruled that it was unconstitutional for states to establish separate schools for Black and White citizens. The Civil Rights Act of 1964 had a profound impact on Black citizens as it was no longer legal for institutions to discriminate against individuals based on race, color, religion, or national origin. The Civil Rights Act of 1968, also called the Fair Housing Act, prohibited discrimination related to the sale, rental, or financing of a home based on race, religion national origin, or sex.

With these institutional constraints removed, the lives of Black Americans have improved, but there are still hindrances rooted in the application of policy in several areas that adversely influence their lives. The "school to prison pipeline," the "glass ceiling" in the workplace, and the challenges of living in inner-city environments still plague many Black Americans and impede chances of upward mobility. Economically, Black households in 2019 lagged all other racial groups in annual earnings at $\$ 46,073$ as compared to Hispanics households at $\$ 56,113$; White households at $\$ 76,057$, and Asian households at $\$ 98,174$ (Wilson, 2019). Black Americans consistently experience rates of 
unemployment that are nearly double the rates of Whites (Byars-Winston, 2010). In 2016, the national unemployment rate for Blacks was $8.4 \%$ in comparison to Whites at 4.3\%. In 2011, following the recessionary period from 2007-2009, the unemployment rate for Black Americans was 15.8\% in comparison to $7.9 \%$ for White American (U.S. Bureau of Labor Statistics, 2011, 2017). The legal system also poses challenges as Black men are targeted through racial profiling and are less able to defend themselves due to financial constraints (Guerino, Harrison, \& Sabol, 2011).

Education has been perceived as the "way out" for citizens in lower economic levels, as obtaining a college degree or technical training consistently leads towards higher paying job positions, and a higher probability of being considered for a promotion. Education level is significant because on average a person with a high school diploma earns \$781 per week, those with a bachelor's degree earns \$1305 per week, and those with a master's degree earns \$1,545 per week (U.S. Bureau of Labor Statistics, 2020). Black workers are achieving more roles in high status occupations, although they are still underrepresented in those same positions.

\section{Statement of the Problem}

Despite being approximately $12 \%$ of the U. S. population, Black people are underrepresented in many higher paying occupations. Blacks represent $5.0 \%$ of physicians (Association of American Medical Colleges, 2019), 5\% of all lawyers (American Bar Association, 2020), 3.8\% of all dentists (American Dental Association, 2020), and 5\% of scientists and engineers in the workforce (National Science Foundation, 2015). Of all the racial groups, this represents the lowest percentage of engineering degrees earned at the bachelor's level (Aud, Fox, \& KewalRamani, 2010). The picture is 
similar when looking at management or professional roles as Blacks make up $9.7 \%$ of the work force (Bureau of Labor Statistics, 2020). Racism is still a major impediment to the career development of Blacks in the workforce (Barrett, 2004). When looking at career mobility, Black Americans have the lowest transition to management due to discrimination, lack of education, and employment with present company (Smith, 2002, 2005). Whites have a noticeable advantage with more options to advance through formal educational programs or informal social networks (Wilson et al., 1999).

Black Americans have made strides in higher education as Blacks make up 13\% of the of the undergraduate population (Postsecondary National Policy Institute, 2020), which is in-line with the percentage of Blacks in the country at approximately $12 \%$. These increases have been seen at the nation's top universities as well where Black students make up $11.3 \%$ of the 2019 freshman class for the top 15 institutions as ranked by U.S News and World Report (2021). As the numbers for Black Americans are improving, Black men appear to have unique impairments compared to Black women. In 2014, Black women represented $3.7 \%$ of the approximately 18,000 total medical school graduates. This is nearly double the percentage of Black men who represented $2.1 \%$ of medical school graduates (Association of Medical Colleges, 2014). Nearly 70\% of Black men do not complete a college degree within six years, which is significantly higher than that of the total undergraduate population at 57\% (Harper, 2006).

For many Black Americans the challenges begin prior to their undergraduate studies. Young people from low-income environments face environmental risk factors such as constrained learning opportunities, limited access to working role models, and negative messages about their abilities and future possibilities (Becker \& Luthar, 2002; 
Kenny, Blustein, Chaves, Grossman, \& Gallagher, 2003; Ladany, Melincoff, Constantine, \& Love, 1997). Studies have shown that these factors can adversely affect academic performance, school attrition, and students' confidence in their own abilities in the classroom (Kaplan, Peck, \& Kaplan, 1997). According to a 50-state report published by the Schott Foundation for Public Education (2015), the estimated high school graduation rate for Black male students was 59\% 2013.

Black men have post-graduate career outcomes that are significantly less than other racial groups, and several social and institutional barriers have been identified that impede their progress. This study attempts to identify internal barriers that may adversely influence the psychology of Black men in relation to their career motivations, aspirations, and their confidence in successfully navigating the career landscape.

The terms African American and Black will be used interchangeably throughout the report. The 2010 U.S. census defines Black or African American refers to a person having origin in any of the Black Racial groups of Africa (U.S. Census, 2011). It is important to note that Black and African American often refer to two different groups of people. The label Black refers to anyone of African descent. This includes people who are the descendants of those who were forced into the transatlantic slave trade and are born in North America, Central America, South American and the Caribbean Island. The term also includes those who are from Africa and do not trace their lineage through slavery. The term African American only refers to Black Americans who were born in the United States and are descendants of people who were enslaved in the United. The term Black encompasses a larger number of individuals from different ethnic groups all of which are of African descent while the label African American refers specifically to 
individuals who are born in the U.S. and are descendants of slaves. The data collected in this study did not differentiate participants by ethnicity and included anyone who selfidentified as Black.

\section{Constructs of Interest}

This study has two purposes. The first is to explore what Black college men believe about their career preparedness, their ability to manage their careers, and how optimistic they are about their career prospects following college graduation. The second purpose is to identify subgroups that represent different sets of beliefs related to career readiness by creating distinct profiles from the constructs Career Adaptability, Career Optimism, Career Decision Making Self-Efficacy, and Impostor Phenomenon. Those profiles will be compared to each other on demographic variables the racial identity subscales of the Multidimensional Inventory of Black Identity (Sellers, e al., 1997) The findings of this study may be used to help colleges and universities develop career intervention strategies aimed at helping Black men prepare for their careers. There is also a dearth of literature published related to the career perspectives of Black college men and this research will contribute to addressing this gap.

\section{Career Adaptability}

Career Adaptability traces it's roots back to the work of Donald Super and his focus on career maturity in his early work in vocational psychology (Super, 1955). Career maturity was a concept that looked at how adolescents prepare for their careers, but it was not descriptive of how adults cope with challenges as they navigate careers. It also led to a focus on the earlier parts of career. Super introduced the term career adaptability in two separate papers published in 1979 with Jennifer Kidd (Super \& Kidd, 1979) and Edward 
Knasel (Super \& Knasel, 1979). Super and Knasel (1981) later defined career maturity as the "readiness to cope with changing work and working conditions" (p. 195). Super's Life Span, Space theory (1990) eventually shifted focus from career maturity and the early stages to encompass an updated focus on career adaptability addressing the necessary attitudes and skills for managing a career throughout the totality of one's career. Although this theory focused on early and later stages career the theory was still perceived as segmented. In 1997, Savickas (1997) suggested that career adaptability could be the bridge that joins the segments.

Savickas (2005) expanded on Super's (1990) theoretical work with the development of Career Construction Theory. This perspective on career development views each person's career path as a function of both personal constructivism and social constructionism. In describing the theory, Savickas (2005) stated of CCT, "It asserts that we construct representations of reality, but we do not construct reality itself' (p. 43). An individual develops their career through adapting to their environment, highlighting that career development is a product of both reactive and proactive behaviors, which Career Construction Theory separates into three categories: vocational personality, life themes, and career adaptability as responses to subjective interpretations to a unique environment.

Vocational personality refers to a focus on vocational self-concepts held by the individual with regard to the career domain. This builds upon the trait aspect of the person-environment fit model (Holland, 1997) by encompassing and focusing on the subjective and idiosyncratic experience of the individual. The life themes component focuses on the perceived self that is constructed through career choices and sees work as "a manifestation of selfhood" (Savickas, 1997, p. 44). Career adaptability refers to the 
attitudes, competencies and behaviors a person employs to find and adjust to work that is meaningful. Savickas (2005) defined career adaptability as "a psychosocial construct that denotes an individual's readiness and resources for coping with current and imminent vocational development tasks, occupational transitions, and personal traumas" (p. 51). In applying career adaptability to the proposed sample, the researcher is trying to capture how college Black men are prepared to adapt to an ever-changing career environment.

\section{Career Optimism}

Career optimism applies the concept of optimism to the career domain.

Rottinghaus et al. (2005) defined career optimism "as a disposition to expect the best possible outcome or to emphasize the most positive aspects of one's future career development, and comfort in performing career planning tasks" (p. 11). The concept of career optimism stems from dispositional optimism (Carver \& Scheier, 1981).

Dispositional optimism refers to an individual's tendency to regularly maintain a positive outlook characterized by expecting good outcomes to occur significantly more than bad outcomes.

\section{Career Decision Self-Efficacy}

Career Decision Self-Efficacy (CDSE) applies Bandura's (1977) self-efficacy construct to the career domain. It was first defined by Taylor and Betz (1983) as a person's belief that she can successfully accomplish the task required to make career related decisions (Lent et al., 1994; Peterson \& DelMas, 2001). An individual's assessment of and belief in their own competence dictates whether or not individuals will engage in specific behaviors (Tang, Pan, \& Newmeyer, 2008). Both distal and proximal factors influence CDSE (Tang, et al., 2008). Distal factors refer to influences that an 
individual experienced during early developmental stages such as family travel, summer camp, or exposure to certain family values (Lent et al., 1994). They refer to all the aspects that affect a person's social conditioning during developmental stages prior to direct engagement in career development process. Proximal factors refer to influences that impact the individual as they are specifically engaged in the career development process such as internship experiences and access to professional networks. Self-efficacy in general, and in the career domain, is subjective to the individual's internal experience, leading them to perform differently based upon the effect the environment has on beliefs (Bandura, 1997).

\section{Impostor Phenomenon}

The impostor phenomenon (IP) is characterized by feelings of intellectual fraudulence especially in high achieving individuals despite their recognized accomplishments (Clance \& Imes, 1978). Individuals will often engage new challenges with fear and anxiety that leads them to procrastinate (Clance, Dingman, Riviere, \& Stober, 1995). Those who fall into this category experience a cycle of procrastination and over-preparation, to relieve the anxiety associated with the task, that often leads to a favorable outcome. Individuals with impostor feelings have difficulty internalizing their achievements and will attribute their success to their ability to fool others rather than as a direct result of their efforts (Clance, 1985). They are also fearful that they will be discovered by others and therefore continually strive for success to maintain their positive public image (Clance \& Imes, 1978). Individuals who experience IP often perceive themselves negatively and believe that others have that same perception (Leary, Patton, Orlando, \& Wagoner Funk, 2000). 


\section{CHAPTER 2}

\section{LITERATURE REVIEW}

The purpose of this chapter is to review the extant literature related to the constructs career adaptability, career optimism, career decision self-efficacy, impostor phenomenon, and racial identity as they relate to Black college men. A brief overview will be provided that explains the development of the operational definitions of the constructs as well as literature that examines each construct within Black populations. This chapter begins with a discussion of career adaptability scholarship highlighting how the construct evolved from Super's (1990) Life Span, Life Space theory of career development and later advances by Savickas' (1997) conceptualization of career adaptability within his emerging Career Construction Theory (2005). That will be followed by a discussion of career optimism. The next section will examine career decision self-efficacy, which will include a brief examination of its roots in Bandura's (1977) self-efficacy theory and its application to vocational psychology (Betz \& Hackett, 1981; Hackett \& Betz, 1981). The review of constructs will conclude with a look at the evolution of impostor phenomenon.

This study explores what Black college men believe about themselves in relation to their careers after college graduation. These constructs were chosen because they each represent an aspect of the self that either directly conveys information related to the career domain or reports on internal constructs that may affect how individuals contemplate their career outlook and pursue plans (Clance \& Imes, 1978; Eva, Newman, Jiang, \& Brouwer, 2020; Savickas, 2005; Sellers et al., 1997; Taylor \& Betz, 1983). The combination of the constructs career adaptability, career optimism, career decision self- 
efficacy, and impostor phenomenon will be used to provide a picture of what Black college men feel and think about their career preparedness, career outlook, and what they believe about their capacity to manage their career successfully. As previously stated, Black men as a whole constitute a small portion of the population in most post-graduate career paths, suggesting that many may not feel welcome or comfortable in higher educational settings. The inclusion of the impostor phenomenon construct will help assess participant's feelings of belonging and their comfort level as undergraduate students while the students are forming their professional foundations.

\section{Career Adaptability}

Career adaptability is rooted in Super's (1990) Life Span, Life Space theory, which focused on both the career related developmental aspects of career and the role work plays in a person's life with the recognition that work is just one of several roles that a person has. This theory is an advancement of Super's earlier work during which he focused on career maturity for career development among adolescents. This eventually became a model with four dimensions of career maturity: foresight, curiosity, knowledge about occupations and careers, and knowledge about the principles of and practice of career decision making. The theory was eventually expanded to encompass the complete life span, but the focus remained on the career development of adolescents thereby limiting its application. The development of the Life Span, Life Space theory intentionally placed an additional focus on the later stages of career development. It examined individuals' career perceptions across four categories: individual differences, development, self, and context. Critics of the theory noted that it was segmented and led practitioners to hyperfocus on developmental aspects of career for younger individuals 
and career identity and the role of work in the lives of older individuals (Brown, 1990; Swanson, 1992). A holistic approach would encourage practitioners to integrate both the Life Span and Life Space aspects of the theory for individuals at all stages of their careers (Swanson, 1992). Ultimately, Savickas $(2005,2020)$ would further Super's work through the development of Career Construction Theory. An early component of that foundation was the focus on adaptation and its role in career development. Savickas (1997) emphasized that adaptability was not a new addition to Super's theory, but an attempt to refocus on an internal component already present:

A broader construct than learning or decision making is already available within the theory, namely, adaptation. Learning and decision making are components of adaptation. Furthermore, adaptation offers a better and more fundamental answer to the functionalist question "What do people do?"- they adapt to their situations. (p. 253) Savickas (1997) goes on to assert that adaptation integrates the individual differences, developmental, self, and contextual segments of Life Span, Life Space theory as adaptability accurately describes what individuals do to improve person-environment fit during all the stages of the career development process. The nature of the postindustrial job market necessitates that workers are prepared to deal with a dynamic work environment. The requirement that this change has placed on modern day workers is directly addressed by the career adaptability construct (Savickas, 2005).

Career Construction Theory represents a shift in focus from personality traits and fit with a particular occupation or career path towards a person's ability to mobilize their own internal resources to meet the dynamic needs of the job market (Savickas, 2020). 
These resources are described as psychological strengths that affect self-regulation in handling tasks, transitions, and traumas (Savickas \& Porfeli, 2012). Past studies have indicated a positive association between the psychological resources characterized by career adaptability and aspects of the school to work transition such as job search selfefficacy, person-environment fit, and employment status (Guan et al., 2013, 2014; Johnston, Luciano, Maggiori, Ruch, \& Rossier, 2013; Pouyaud, Vignoli, Dosnon, \& Lallemand, 2012; Rossier et al., 2012; Zacher, 2015).

Career adaptability is a significant internal construct necessary for successfully engaging a dynamic work environment (Hall \& Mirvis, 1995; Savickas et al., 2009). Savickas (1997) defined career adaptability as "the readiness to cope with the predictable tasks of preparing for and participating the work role and with the unpredictable adjustments prompted by changes in work and working conditions" (p. 254). Within Career Construction Theory, Savickas (2005) described career adaptability as beliefs, attitudes and competencies grouped in four dimensions: concern, control, curiosity, confidence. Concern refers to the regard an individual has toward their future career; control relates to developing the personal agency to shape career purposely; curiosity denotes a person's desire for career exploration and confidence, addressing an individual's likelihood to actively seek out favorable career opportunities. Each of these dimensions encompasses its own set of attitudes, behaviors and competencies. These, in turn, impact the coping methods employed within each dimension of the construct. Career adaptability refers to an individual's ability to be self-motivated to develop the skills and attitudes necessary to solve challenges throughout their career (Savickas \& Porfeli, 2012). 
There have been two instruments created that measure career adaptability: The Career Adapt-Abilities Scale (CAAS; Savickas \& Porfeli, 2012), which draws directly from Career Construction Theory and the Career Futures Inventory (CFI; Rottinghaus, Day, \& Borgen, 2005). Savickas and Porfeli (2012) created the CAAS, which is comprised of 24 questions across subscales concern, control, curiosity, and confidence. Maggiori, Rossier, and Savickas (2015) developed a short form of the CAAS consisting of 12 items. The Career Futures Inventory (CFI; Rottinghaus et al., 2005) includes an 11item career adaptability subscale. Rottinghaus et al. defined adaptability as "the capacity to cope with and capitalize on change in the future, level of comfort with new work responsibilities, and the ability to recover when unforeseen events alter career plans" ( $p$. 11). This definition integrates dimensions of career adaptability and positive psychology. In the CFI, future perspectives on career are assessed across three scales Career Adaptability, Career Optimism, and Perceived Knowledge. While drawing on similar definitions of the multifaceted construct of career adaptability, the measures have two different perspectives as the CAAS sees career adaptability as internal strengths and the CFI career adaptability subscale conceptualizes career adaptability as a more stable set of personal beliefs. To date, neither of these scales has been used on an Black population. This study will add to the literature by using the Career Adaptability scale from the CFI on a sample of Black male college students. 


\section{Career Decision Self-Efficacy}

According to Bandura's (1977) four sources of self-efficacy, a person's selfefficacy beliefs are generated and shaped through the development of skills, the experiences of others, increased awareness through verbal persuasion, and the impact of emotions in relation to experiences or ideas. Increased mastery through direct experience is particularly influential as it validates self-efficacy beliefs with evidence (Bandura, 1997). Schunk and Ertmer (2000) found that students' past results were an accurate proxy for measuring self-efficacy. Performance appears to positively relate to self-efficacy beliefs in students (Zimmerman \& Ringle, 1981).

The environment and the related perceptions held by individuals have a key influence on self-efficacy in the career domain. In a study of CDSE in 220 Black college students, Chaney, Hammond, Betz, and Multon (2007) found that CDSE is inversely related to career alternatives, career indecision, vocational exploration behaviors, and vocational identity. The findings related to career indecision and career exploration validated previous research, which found that CDSE was inversely related to vocational indecision (Taylor \& Pompa, 1990) and self-efficacy was related to career exploration (Blustein, 1989).

Cultural mistrust has been shown to have a relationship to CDSE. BullockYowell, Andrews, and Buzzetta (2011) analyzed the intersection of personality and dysfunctional career thoughts and cultural mistrust in a sample of 322 college students in which 54\% were African American and 44\% were White. Cultural mistrust was defined as the trust level held by African Americans towards European Americans (Terrell \& Terrell, 1981). In the subsample of African American students, they observed that 
cultural mistrust was negatively correlated with CDSE.

Career exploration is a developmentally important task for college students and young adults, that demonstrates an association with mental health. In a sample of 388 students, Rottinghaus, Jenkins, and Jantzer (2009) found that students who were undecided in their choice of major were significantly more depressed than those who had chosen a major. Walker and Peterson (2012) found similar results in sample of 158 college students in which they examined their association between dysfunctional thoughts, occupational indecision, and depression. The findings indicated that both dysfunctional career thoughts and occupational indecision where positively correlated to depression, with decision making confusion being the strongest predictor. Mental health factors such as depression or distress will not be measured in the current study, but the impostor phenomenon will be used to identify mental distress related to individuals' comfort in their present environment. The studies which have shown a negative correlation between mental health distress and career exploration may suggest a similar finding related to the impostor phenomenon.

External factors have been shown to impact CDSE as well. In a study of 396 African American high school students, Austin (2010) found that among age, gender, year in school, GPA, and living situation only SES showed a significant relationship with CDSE. Prior studies have shown that SES influences students in several areas including a greater possibility for rich educational opportunities, increased career adaptability, and greater access to resources (Blustein et al., 2002; Maher \& Kroska, 2002). Decreased career options, often associated with lower SES populations, has been linked to lower career self-efficacy in minority students (Boris-Rangel et al., 1990; O'Brien et al., 2000). 
High CDSE appears to have a positive relationship with career outcomes such as vocational identity and career exploration behaviors in African American high school students (Gushue, Scanlan, Pantzer, \& Clarke, 2006), highlighting the need for the development of interventions and techniques that bolster CDSE in students early in the formation of their thoughts about career.

Research on the connection between CDSE and ethnicity is somewhat mixed as Brown Darden, Shelton, et al. (1990) found that that minority status inversely correlated with the CDSE of the students who were the numeric minority regardless of race. In a sample of 102 ninth grade Black and Latinx girls, Gushue and Whitson (2006) found a positive relationship between ethnic identity and CDSE, and gender role attitudes indicating that to the extent they can integrate their race, ethnicity, and gender roles they may display a stronger belief in their ability to navigate the career decision process. Gushue (2006) found similar results in a study of 128 Latinx ninth graders in which findings indicated that ethnic identity had a direct and positive association with career CDSE. In a study of 104 Black students, Bounds (2017) observed a significant positive correlation between CDSE and ethnic identity.

\section{Career Optimism}

The concept of career optimism (Rottinghaus, Day, \& Borgen, 2005) stems from dispositional optimism, which was established by Carver and Scheier (1981). Dispositional optimism refers to an individual's tendency to regularly maintain a positive outlook characterized by expecting good outcomes to occur significantly more than bad outcomes. Adaptive career planning strategies have been found to be positively linked to dispositional optimism (Creed, Patton, \& Bartum, 2002). An optimistic outlook is 
associated with increased levels of self-esteem, engagement in problem solving coping strategies related to the career domain, higher confidence in relation to their career choices, a greater number of career goals, and decreased level of psychological distress (Creed et al., 2002; Strutton \& Lumpkin, 1992). A pessimistic outlook tends to lead to decreased psychological health and impairments in vocational pursuits (Eva, Newman, Jiang, \& Brouwer, 2020).

Studies indicate that optimistic individuals may be better able to adjust to new situations because they are flexible when assessing and using information (Aspinwall, Richter, \& Hoffman, 2001). Carver and Scheier (2001) suggested that pessimists may be more apt to decrease their efforts in achieving stated goals. Researchers have stated that an optimistic perspective may favorably impact career plans (Creed, Patton, \& Bartrum, 2002; Lucas \& Wanberg, 1995; Marko \& Savickas, 1998; Savickas, Silling, \& Schwartz, 1984). It also correlates positively with workplace variables, including job satisfaction, organizational commitment, and work performance (Kluemper, Little, \& Degroot, 2009; Yousseff \& Luthans, 2007).

A measure to assess optimism specific to the career domain was developed by Rottinghaus et al. (2005). In their initial study to construct and validate the scale they found that in college students, career optimism is positively associated with GPA, comfort in engaging both academic and career plans, and participating in activities that enhance insight related to career. Career optimism also positively related to career exploration, career choice status, and career aspirations (Rottinghaus, Buelow, Matyja, \& Schneider, 2012; Rottinghaus et al., 2005), adjustment to college (Aspinwall \& Taylor, 1992), and satisfaction with choice of college major (McIlveen, Beccaria, \& Burton, 
2013). Career optimism has shown to have a positive moderate association with career adaptability (Rottinghaus et al., 2005). Garcia et al. (2015) examined the influence of parental support, teacher support, and CDSE on career optimism and found that CDSE mediated the influence that both parental support and teacher support had on career optimism. The direct relationship between support and career optimism disappeared when accounting for CDSE, indicating that support increases self-efficacy in the career domain, which then increases career optimism. Thus far, no studies have focused on assessing career optimism in African American male collegiate population or any other ethnic minority group. This particular study will contribute to the literature by measuring career optimism in Black male college students.

\section{Impostor Phenomenon}

Studies have shown that IP is correlated with several adverse mental health conditions, including depression (Clance \& Imes, 1978; Thompson, Davis, \& Davidson, 1998), psychological distress (Henning, Ey, \& Shaw, 1998), anxiety (Topping \& Kimmel, 1985) and poor overall mental health (Sonnak \& Towell, 2000). Other studies have associated increased IP with low global self-esteem (Chrisman, Peiper, Clance, Holland, \& Glickhauf-Hughes, 1995: Cozzarelli \& Major, 1990; Thompson, Davis, \& Davidson, 1998), and both increased perfectionism (Henning et al., 1998) and racial identity attitudes (Ewing Richardson, James-Myers, \& Russell, 1996).

Impostor feelings have been found to exist among ethnic minority students (Cokley et al., 2013; McClain et al., 2016; Peteet, Montgomery, \& Weekes, 2015; Peteet, Brown, Lige, \& Lanaway, 2015). Cokley et al. (2013) found that impostor feelings were a predictor of psychological distress and psychological well-being in an ethnically 
diverse sample of college students that included Asian American, African American, and Latinx Americans. Cokley and his colleagues (2013) also found that impostor feelings decreased the effect of minority status stress on psychological distress and psychological wellbeing. In a later study, Cokley et al. (2017) found that in students who have high impostor feelings there is a strong positive relationship between perceived discrimination and depression.

The past studies have measured IP with regard to college students and mental health, ethnicity, and minority status but thus far there have not been studies examining IP and career related constructs. This study attempts to add to the research by investigating the role that IP may play in the career development of African American male college students.

\section{Racial Identity}

In looking at Black college men and career preparedness, this study sought to observe to what degree participants' racial identity influenced their outlook on their own careers. The construct of racial identity refers to how an individual feels about their membership in their racial group and the associated experiences (Cross \& Cross, 2008; Sellers, 1993; Sellers, et al.,1997). Black racial identity has been assessed from multiple perspectives over time. Though there are several models that attempt to describe racial identity, the Multidimensional Model of Racial Identity (MMRI; Sellers, et al. 1997) was used to provide a framework for this study. This model represents the latest evolution of scholarship focused on the self-concept and how it is impacted by race for Black people.

The roots of racial identity scholarship are largely based on social psychology's exploration of prejudice. Gains and Reed $(1994,1995)$ recognized two different strands 
of early research into racial identity which they labeled mainstream and underground. The mainstream approach focused on the African Americans' oppressed status in the broader U.S. society and less on the impact of culture (Clark \& Clark 1939; R. Horowitz, 1939). This perspective assumed the stigmatized nature of race would negatively impact Black individuals by leading them to develop inferiority complexes based on race. This assumption was believed to bring congruence between how Black people were treated and how they felt about themselves. Another perspective developed as Black psychologists began to study Black racial identity with a focus on culture and racially based oppression (Cross, 1971; Thomas, 1971; Jackson, 1976; Parham \& Helms, 1981).

This type of research, which focused on how experiences and culture shaped how Black people perceived their own sense of Blackness in the context of oppression within the U.S., was called the underground approach. This perspective did not assume that selfhatred was an inherent part of the Black identity. This view was supported by the development of new measures for self-esteem that showed that African Americans did not necessarily have low self-esteem (Porter \& Washington, 1979; Rosenberg \& Simmons, 1971; Taylor \& Walsh, 1979).

The first models of Black racial identity stem from the line of research associated with the underground approach and were developed in the 1970s. Charles Thomas (1971), William Cross (1971), and Bailey Jackson (1976) each developed models that attempted to describe Black people's psychological experience with a focus on how they were affected by both African American and broader mainstream cultures. These early theories were stage models which focused on the process that occurs over time as Black people's psyche are impacted by the world. Cross (1971) developed the Nigrescence five- 
stage model which described the process of becoming Black. It was initially called the Negro to Black conversion experience. Negromachy is a five-stage model developed by Charles Thomas (1971) that described a person's transformation from racial rejection to racial acceptance. The term Negromachy referred to a form of mental illness in which individuals rejected their racial identity. Jackson’s (1976) Black Identity Development, another five-stage model, was developed with the specific goal of understanding Black people's experience to facilitate the creation of interventions to assist in the advancement of individual groups and systems. All three of these models assert that Black identity is shaped by the impact of experiences with mainstream community that often reflect a negative outcome based upon prejudices held against Blacks leading to discrimination. This impact leads a person to question their role in the community with regard to race and eventually, as they move through the stages, internalize a positive Black self-image which allows them to feel positive esteem towards a Black identity while trying to negotiate a difficult and even hostile racial environment.

Cross's (1971) Nigrescence model received the most attention in the field due to the creation of the Racial Identity Attitudes Scale (RIAS; Parham \& Helms, 1981), which was developed using the Nigrescence model. The five stages of Nigrescence are Preencounter, Encounter, Immersion-Emersion, Internalization, and InternalizationCommitment. The pre-encounter stage is characterized by negative feeling towards Blackness and a perspective in line with the broader White community. The encounter stage is when individuals have negative experiences related to race that lead them to question their attitudes and perspectives. During the immersion-emersion stage a person adopts a pro-Black attitude while questioning and disparaging White culture. The 
internalization stage is characterized by a decrease and eventual extinguishing of antiWhiteness, while internalizing a stable sense of Blackness. The final stage of internalization-commitment is marked by activities and attitudes that support social justice for all. Helms (1990) used Cross' Nigrescence model as a foundation for her model, the Psychodiagnostic Model of Racial Identity Development, which shifted the focus of each stage to reflect an ego-based perspective. This model assumed that people make sense of racial information based upon their own worldview. This model described the emotional, behavioral, cognitive associations related to each ego status.

While Cross' Nigrescence model was popular, it was critiqued for the assumption that most people move through stages in a linear fashion. In addition, the first stage of the model, pre-encounter, assumes that Blacks have internalized a negative view towards their Black community. This does not account for individuals who have not developed a negative view possibly because they were raised in a predominantly Black community that not only protected them from negative views about Blackness but may have affirmed their Black identity. The model was later revised to allow more flexibility and complexity to describe the ideologies held by individuals in different stages (1991). The first stage called pre-encounter stage was amended to include the ideologies of assimilation, miseducation, and self-hatred. The third stage called immersion-emersion, now includes two categories, anti-White and Black involvement. The fourth and final stage internalization, was amended to include Black Nationalist, biculturalist, and multiculturalist ideologies. The final stage of internalization-commitment was eliminated because there appeared to be very little difference between the fourth stage, Internalization, and the fifth stage, Internalization-commitment (Cross, 1991). This 
revision also led to the creation of the Cross Racial Identity Scale (CRIS) which was developed to reflect the changes made to the Nigrescence model (Vandiver et al., 2000). The CRIS was also developed to address critiques of the RIAS related to low reliability and construct validity (Ponterotto \& Wise, 1987).

The previous process models represent how Black racial identity theory has evolved over time. Only the revised version of the Nigrescence model included the content of individual's perspectives related to ideology and beliefs. In contrast, the most recent theory to describe racial identity is a content model called the Multidimensional model of Racial Identity (MMRI), which emphasizes what individuals think about themselves from a racial perspective in relation to both Black and White communities (Sellers, et al., 1998). There are four assumptions underpinning this model. First, Black racial identity is assumed to be both situationally defined and stable. Therefore, based upon experience, some environments will influence individuals to perceive their race as more salient than others. This also suggests that prior experiential factors will lead individuals to perceive differences in salience in similar environments (Sellers et al.,1998). Second, individuals have a number of different identities and that these identities are hierarchically ordered. The model does not assume that race is the most important identity for an individual. The third assumption is that an individual's perception of their racial identity is the most valid indicator of their identity. And lastly, the model assumes individual differences in perceptions of what it means to be Black. Comparatively, the stage models described the transition of the self-concept regarding race as one from "good" to "bad" or one from "unhealthy" to "healthy." The MMRI does not imply a judgment on what defines a healthy racial identity (Sellers et al., 1997) 
The MMRI focuses on the content of attitudes held towards inclusion in the Black racial group along four dimensions, labeled Centrality, Regard, Ideology, and Salience (Sellers, 1993). Racial centrality refers to how individuals connect to race when defining themselves and is considered to be a stable trait. Racial regard is divided into two categories Private and Public. Private Racial regard refers to how the individual feels towards the Black community and Public Racial regard refers to how the individual thinks others feel towards the Black community. Ideology has four categories which refer to how an individual thinks that members of the Black community should relate to those within the Black community and those without. The Nationalist ideology espouses the view that the Black experience is unique and that the Black community should be in control of their own self-determination. The Oppressed Minority ideology recognizes the oppression experienced by both Blacks and other minority groups. The Assimilationist ideology describes Blacks who recognize the similarities between Blacks and other Americans. They endeavor to enter the mainstream community as much as possible (Sellers et al.,1998). The Humanist ideology describes a perspective that sees the common humanity across all groups.

Since the focus of this study is to observe Black college men's attitudes towards their career preparedness, the MMRI was chosen to observe Black racial identity in the sample because of its focus on breadth of content. It allows for individuals to hold a variety of viewpoints across multiple dimensions which should help to facilitate the heterogeneous profiles in a racially homogenous sample. The MMRI also does not group individuals based on developmental progression stage which is important because the sample in this study are already part of restricted age range. 


\section{Need for Present Study}

There are several gaps in the literature related to the constructs of interest in relation career and African American male college students. This exploratory study will add to the discourse in relation to those gaps while also providing a detailed and informative profile of African American college men that will be useful for practitioners in vocational psychology as well as administrators in student affairs at colleges and universities. The profiles developed from data collected in the present study may indicate how Black college men rate themselves in relation to career preparedness, as indicated by career adaptability, career optimism, and career decision making; and how comfortable they feel in the academic environment as measured by the impostor phenomenon. The scores on these measures will be used to investigate relationships with demographic variables in order to identify groups of students that show significant perceived strengths or weakness with regard to their beliefs about their vocational readiness or outlook. As noted in Chapter 1, African American men are significantly underrepresented in many of the professions and the associated professional schools. The information examined in this study may be used to develop interventions that help to prepare men to contemplate, explore, and enter fields where Black men are currently underrepresented. 


\section{CHAPTER 3}

\section{METHOD}

To examine the perspectives that African American college male students hold towards their careers an exploratory study was conducted to measure career optimism, career adaptability, career decision self-efficacy, the impostor phenomenon and racial identity in a sample of Black college men. The intent of the study was to develop profiles in the sample based on the career related constructs and the impostor phenomenon that can be used to identify the strengths and weaknesses related to how prepared Black men feel to choose and pursue a career. Racial identity and demographic data were used to observe how their Black racial identity and background may influence the development of the profiles. These profiles will represent the range of career preparedness that Black men have with regard to their future careers. Cluster analysis was used to create the profiles as it is designed to create groups that have high homogeneity within the groups and high heterogeneity between groups.

\section{Participants}

The sample consisted of 228 Black male university students. Neither sample size nor specific guidelines on how to determine sample size estimates were noted in several studies using cluster analysis (e.g., Borgen \& Barnett, 1987; Everitt, Landau, Leese, \&

Stahl, 2011; Gore, 2000). The sample's overall representation of the targeted population is what is most important as cluster analysis does not rely on statistical probability for inference testing.

The majority of students, 220 (96.5\%), attended predominantly White universities and six students $(3.5 \%)$ reported attending a historically Black college or university. 
Regarding academic classification, students in the sample included 66 (28.9\%) freshmen, $52(22.8 \%)$ sophomores, 51 (22.4\%) juniors, and 59 (25.9\%) seniors. A significant majority of the students $207(90.8 \%)$ reported that they had declared an academic major while $21(9.2 \%)$ indicated that they had not. With regard to graduate school intentions, 80 students $(35.1 \%)$ indicated having no intention to pursue graduate education, 71 students (31.1) indicated interest in a master's degree, 14 students (16.1\%) a law degree, 27 students (11.8\%) expressed interest in a medical degree (MD, DDS, DVM), and 36 students (15.8\%) expressed interest in pursuing a doctoral degree. Students from the suburbs represented $86.8 \%$ of the sample. Participants reported on the educational attainment of both of their parents, with 96 (42.1\%) mothers or female guardians having earned a least a bachelor's degree and $84(36.8 \%)$ fathers or male guardians accomplishing the same. Data on family income level were also collected and $61(26.8 \%)$ participants reported a family income of less than $\$ 35,000$ and $25(22.8 \%)$ had an income level of $\$ 100,000$ or greater. Students were asked about their own educational aspirations and $65.2 \%$ of the sample indicated an intention to pursue a graduate degree.

\section{Materials}

Demographic Characteristics of the Sample. As part of the data collection process, the students completed a demographic questionnaire that recorded their classification in school, family household income, mother's educational attainment, father's educational attainment, environmental background (urban, suburban, or rural environment), educational aspirations, age, educational aspirations, career aspirations, and major decision status.

Career Futures Inventory (CFI). The CFI (Rottinghaus et al., 2005) is a 25-item 
measure that assesses career optimism (CO), career adaptability (CA) and perceived knowledge of the world of work (PK) (see Appendix B). The CO subscale consists of 11 items, the CA subscale consists of 7 items, and the PK scales has 3 items. The CFI uses a 5-point Likert-type scale ( $1=$ strongly disagree; $5=$ strongly agree $)$ to assess the degree to which students agree with item. Rottinghaus et al. (2005) reported internal consistencies of: $\alpha=.87$ for $\mathrm{CO} ; \alpha=.85$ for $\mathrm{CA}$; and $\alpha=.73$ for PK. Other studies have supported the convergent and criterion validity of the CO scale (McIlveen et al., 2013; Tolentino et al., 2014). The CO scale attempts to measure how optimistic a person is towards their career development. An example of an item from this subscale is "I get excited when I think about my career." The subscale CA attempts to capture a person's views of their ability to plan and adjust to changing career plans and work responsibilities. An example of an item from this scale is "I can overcome potential barriers that may exist in my career" Students were given the items from the perceived knowledge subscale although the subscale was not used as a clustering variable or in any part of the analysis. Both the $\mathrm{CA}(\alpha=.83)$ and $\mathrm{CO}(\alpha=.80)$ subscales showed internal consistency.

Career Decision Self-Efficacy (CDSE-SF). Career decision self-efficacy will be assessed using the 25-item short form of the Career Decision Self-Efficacy Scale-Short Form (see Appendix C) (CDSE-SF; Betz, Klein, \& Taylor, 1996). The CDSE-SF uses a 5-point Likert-type scale ( $1=$ no confidence at all; $5=$ complete confidence $)$. The career decision self-efficacy scale attempts to measure how much belief an individual has in their ability to complete tasks necessary to making career decisions. A sample item from this scale is "How much confidence do you have that you could find information in the 
library about occupations you are interested in?" The scale has an internal consistency reliability estimate of $(\alpha=.94)$ with concurrent validity estimates ranging from 0.40 to 0.66 with vocational identity (Betz et al., 1996). The scale displayed high reliability with this sample as well with $(\alpha=.94)$. The scale was developed from the five career maturity competencies outlined by Crites (1978) which are accurate self-appraisal, gathering occupational information, goal selection, planning, and problem solving.

Clance Impostor Phenomenon Scale (CIPS). Clance Impostor Phenomenon Scale (CIPS; Clance \& Imes, 1978). The impostor phenomenon is assessed using the CIPS. The CIPS is a 20-item scale that measures feelings of being a fraud or an intellectual phony (see Appendix D). The items are rated on 5-point Likert type scale $(1=$ not true at all, $5=$ very true). A sample item is "I can give the impression that I'm more competent than I really am." The CIPS has evidence for good reliability $(\mathrm{a}=0.96)$ and convergent validity in a gender and ethnically heterogeneous sample, and it distinguishes between individuals who identified as having impostors feelings and those how do not (Chrisman, Pieper, Clance, Holland, \& Glickauf-Hughes, 1995; Holmes, Kertay, Adamson, Holland, \& Clance, 1993). The CIPS demonstrated high internal consistency with the current sample $(\alpha=92)$.

Multidimensional Inventory of Black Identity (MIBI). To explore racial identity the Multidimensional Inventory of Black Identity was (MIBI) was used, which is a scale that operationalizes the Multidimensional Model of Racial Identity (MMRI). The MMRI is a content racial identity model that assess the attitudes, beliefs, and perspectives a person holds toward their own race. The MIBI measures three of the four dimensions defined in the MMRI: racial centrality, racial regard, and racial ideology. Salience is the 
fourth dimension of the MMRI and is not includes in the MMBI because salience not considered to be stable and is reflective of the situations an individual is exposed to. The MIBI has seven subscales Centrality, four ideology subscales (Nationalist, Oppressed Minority, Assimilationist, and Humanist) and two regard subscales (Private and Public). Racial centrality refers to how individuals connect to race when defining themselves, racial regard refers to perception of their own race, and ideology relates to the meaning an individual gives to being Black (Sellers et al., 1998).

The MIBI represents these racial identity dimensions through the use of seven subscales. Each of the subscales consists of eight items each on a 7-point Likert type scale $(1=$ strongly disagree, $7=$ strongly agree $)$. The centrality scale measures the degree to which race is important to the person and to what extent being African American is an important part of one's identity. An example question from the Centrality subscale is "In general, being Black is an important part of my self-image.” A higher score indicates that a person feels that race is a more central identity. The internal reliability on this scale for the sample was $(\alpha=.74)$. The private regard subscale reflects how an individual feels about being African American with higher scores representing more positive views. An example question from the Private Regard subscale is "I feel good about Black people." The internal reliability on this scale for the sample was $(a=.82)$. The public regard subscale indicates the extent to which a person feels that other people view African Americans either positively or negatively (Sellers, et al.,1997). An example question from the Public Regard scale is “Overall, Blacks are considered good by others." Higher scores indicate that an individual thinks other people tend to have more positive feelings toward African Americans and lower scores indicate that a person perceives that other 
races have more negative feelings towards African Americans. The internal reliability on this scale for the sample was $(\alpha=.71)$.

Racial ideology is measured by the subscales Nationalist and Assimilationist. Nationalist is a perspective that emphasizes the importance of being of African descent and highly values the needs and values of the Black community. An example of a question from the Nationalist subscale is "Black people should not marry interracially." The internal reliability on this scale for the sample was $(\alpha=.77)$. Assimilationist is an ideology that values the similarities between the broader society and African Americans. An example of a question from the Assimilationist subscale is "Blacks should strive to be full members of the American political system." Higher scores on the Assimilationist subscale represent higher endorsement of assimilationist views and higher scores on the Nationalist subscale indicate higher alignment with that ideology (Sellers et al., 1997). The internal reliability on this scale for the sample was $(\alpha=.72)$. The Humanist subscale measures how much an individual emphasizes the similarities in all races with higher scores reflecting higher emphasis on similarities. An example of a question from the humanist subscale is "Black values should not be inconsistent with human values." The internal reliability on this scale for the sample was questionable $(\alpha=.62)$. The Oppressed Minority subscale measures the degree a person places emphasis on the similarities between African Americans and other minority groups with higher scores indicating a higher emphasis. An example of a question from the oppressed minority subscale is "Blacks should learn about the oppression of other groups." The internal reliability on this scale for the sample was $(\alpha=.77)$. 


\section{Procedure}

Data Collection. The study was submitted to the IRB committee of the researcher's University for approval before the recruitment process was initiated. The students were recruited from a diverse sample with no criteria for specific majors or course of study. The students were recruited through contacting Black student organizations, and Black student affairs professionals at targeted universities. The institutions were selected based on convenience sampling. The primary researcher had personal connections with professionals at some institutions and the primary investigator researched institutions on the internet and contacted student affairs professionals who appeared to have access to Black male students. One method of recruitment was the Black Male Initiative. The Black Male Initiative is an organization created to support Black male college students and there are chapters of this organization at many schools across the country. The primary investigator contacted faculty sponsors of this organization at 19 universities who agreed to distribute the survey. After contact with individuals at the universities were established, they were sent an email with an introduction from the primary investigator and a link to access the survey via an online Qualtrics survey. As an incentive, students who participated in the study were given a \$10 electronic Amazon gift card. Once students completed the survey, they were asked to provide their email address and were then sent an electronic gift card.

The initial sample consisted of 372 students. However, a total of 158 students were removed from the study because they did not fit the inclusion criteria parameters leaving a final sample population of 228 . The responses from 4 students were removed because they did not identify as male, 19 students because they were older than 25 years 
old, 4 students were deleted because they were under the age of 18, 3 students because they did not identify as Black or African American, 1 student who attended a community college, and 7 students because they were graduate students. The data from 106 students were deleted because they finished the entire survey in fewer than eight minutes, implying that they did not read and process each question and filled the survey out as quickly as possible. The students in the final sample came from 21 schools from the South, Midwest and Eastern regions of the country (See Figure 7 and Table 6).

Several of the categories that were collected on the demographic of the survey section were recoded to facilitate data analysis. Both of the variables Mother's and Father's educational attainment initially offered nine categories denoting different educational levels from "unknown" to "Doctorate (MD/PhD)." For the purpose of analysis, the categories were modified as follows: "Some High School" = 1; "High School Graduate" = 2; "Some College" = 3, "Associates" = 4, "Bachelor's" = 5, "Master's" = 6, "Law Degree" and "Doctorate $(\mathrm{MD} / \mathrm{PhD}) "=7$.

The variable "Environmental Background" was initially broken down into five categories: "Urban," "Suburban," "Rural," "Small Town," and "Other." This resulted in having only 7,16 , and 9 participants for the categories "Rural," "Small Town" and "Other," respectively. The categories "Rural" and "Small Town" were combined into one category with 23 participants and the "Other" category was not included in the analysis because it is not possible to know what the participant meant when they marked this category. The variable "Educational Aspirations" was initially divided into six categories: “Bachelor's Degree (4-year BA/BS)," "Master's Degree (MA/MS)," "Law Degree (JD)," “Medical Degree (MD, DDS, DVM)," and "Doctorate (Ph.D., Ed.D).” For the purposes 
of analysis this was divided into to three categories: Bachelor's, Master's, and doctorate, which included “Law Degree (JD)," “Medical Degree (MD, DDS, DVM),” and “Doctorate (Ph.D., Ed.D)."

Data Analysis. The data were assessed using cluster analysis to separate the participants into groups based upon the different constructs assessed in the measures. Cluster analysis has been shown to be an effective method to help researchers identify groups of individuals who are similar based up on factors of interest (Borgen \& Barnett, 1987). The process resulted in profiles that evolved from the data, which demonstrated patterns of how Black college men perceive their future careers. The process of cluster analysis groups participants into clusters differentiated by how the participants scored on the variables being measured. The goal of the process is to provide structure to the data by separating the participants into groups that have high within group similarity and are highly dissimilar between groups (Hair \& Black, 2000). These groups will be formed and labeled in relation to characteristics of the factors designated by the nature of the grouping.

Clustered data is traditionally analyzed using methods categorized as hierarchical, nonhierarchical, or a combination of both (Seber, 1984). As suggested by Gordon (1999), there were two stages to the process of analyzing the data. During the first stage, the data was grouped into clusters using a hierarchical method to find the number of clusters that initially form around the clustering variables, CA, CO, CDSE, and IP. There were several cluster options suggested through the visual observation of a dendrogram which resulted from the initial hierarchical procedure. Then in the second stage a non-hierarchical method called k-means clustering was used to observe the groupings of each of the 
different numbered cluster solutions. The final 6-cluster solution was chosen. There is not necessarily one correct way to analyze clustered data and multiple methods may all result in useful information. To ensure that one measure did not have more influence over the data than another, due to scale, all of the data was standardized as part of the clustering process. After the final 6-cluster solutions was selected, the clusters were compared using the subscales from the MIBI and the data collected from the demographic questionnaire. 


\section{CHAPTER 4}

\section{RESULTS}

This chapter presents the summary of the data analysis and statistical results from the data collected in the current study. The analysis begins with an assessment of the descriptive statistics and reliability estimates for the primary measures included in the study. Cluster analysis was the primary tool used to separate the data into homogenous groups and this was completed in two steps. The first was to use hierarchical cluster analysis to determine a starting point for choosing the appropriate number of clusters. Second, k-means clustering was used to separate the data into the clusters suggested by the hierarchical clustering procedure. Next, the differing clusters solutions were compared to determine which cluster solution best describes the data. Lastly, the clusters within the final cluster solution were used to compare group differences on racial identity, mother's educational level, father's educational level, family income, age, year in school, environmental background, educational aspirations, and major decision status.

\section{Descriptive Statistics and Reliability Estimates}

Table 1 lists the bivariate correlations, reliability estimates, means, and standard deviations for the variables of interest. The career related scales Career Optimism (CO), Career Adaptibility (CA), and Career Decision Making Self-Efficacy (CDSE) were all significantly positively correlated with each other $(p<.001)$. The Impostor Phenomenon (IP) scale had a significant negative correlation with CO $(p<.001)$. Analysis indicated good internal consistency for all the clustering variables with Cronbach's alphas of $.92, .83, .80$, and .94 for IP, CO, CA, and CDSE, respectively. The racial identity subscales showed lower internal consistency with subscales Central, Private Regard, 
Public Regard, Assimilation, Humanist, Minority, and Nationalist with Cronbach's alphas of $.74, .82, .71, .72, .62, .77$, and .77 respectively.

\section{Cluster Analysis}

Cluster analysis was used to identify profiles within in the sample based on career related constructs. IBM SPSS software version 26 was used to conduct the analysis. The grouping variables were CDSE, CO, CA and IP. The groups were identified using hierarchical analysis to create clusters using Ward's clustering method, which seeks to minimize within group differences while maximizing between groups variability as measured by Euclidean distance. To prevent a possible bias using Ward's method due to scaling differences between measures all scores were standardized using Z-scores (Borgen \& Barnett, 1987). The change coefficients in the agglomeration schedule showed the biggest change when going from three to four clusters. A visual inspection of a dendrogram suggested that there may be support for a three, four, five, six, or seven cluster solution. K-means clustering was used to compare the effectiveness of each of those possibilities and a six-cluster solution was chosen. A three-cluster solution was not considered because it grouped the data into clusters of high, medium, and low. The four and five cluster solutions showed more variation, but the six-cluster showed the most differentiation with four of the six clusters having an average IP score plus or minus one standard deviation. The seven-cluster solution displayed similar results, but the clusters sizes were smaller with the two smallest groups having only 12 and 17 participants. The final decision regarding the number of clusters to be used was determined based on parsimony and explanatory power, therefore a six-cluster solution was chosen. 
The final six-cluster solution differed significantly on all variables $(p<.001)$. See Table 2 for final cluster mean centers, standard deviations, skewness, and kurtosis. See Figure 1 for a bar graph representing the measured scales in each cluster. Cluster 1 is characterized by above average IP scores and the lowest scores for CO and CDSE. Cluster 2 is comprised of above averages scores on all variables. Cluster 3 is defined by nearly average scores on all of the career-related measures and below average scores on IP. Cluster 4 consists of average IP scores and below average scores on the career-related variables with the lowest score of all clusters for CA. Cluster 5 is characterized by above average scores on the career-related variables and below average scores on IP. Cluster 6 consists of an above average IP score and approximately average scores on the career related variables.

\section{Cluster Descriptions}

In this section I will describe and label the clusters based upon the mean scores of the scales that were observed in each cluster. See Table 3 for a listing of all labels for each cluster. Cluster 1 is the smallest cluster with 14 participants. It has higher than average IP mean scores reaching nearly one standard deviation. Both the CO and CDSE scores are over one and a half standard deviations below the mean. The CA mean score is near the total group mean. This cluster is labeled the "impostor with low optimism and career agency." These scores indicate the students do not feel that they belong in their current environment and lack both hope and agency towards their career futures.

The second cluster is the second largest with 47 participants and has IP scores one standard deviation above the sample average and scores on the career-related scales that are approximately one standard deviation above the sample average. This cluster is 
labeled "highly prepared impostor" as their impostor feelings appear to be high as well as their belief in their readiness to navigate the career landscape.

The third cluster is the largest cluster with 68 participants. The participants in this cluster have lower than average IP scores, approximately three quarters of a standard deviation below the mean. The rest of the scores are right at the average except for the CDSE mean score which is approximately one quarter of a standard deviation below the average. This cluster is called "comfortable" as their IP scores indicate the students are more comfortable than most in their present environment and they have average scores on the career constructs indicating neither a lack of nor abundance of belief in their career readiness in comparison to the sample.

Cluster 4 has 34 participants who reported below average scores on all the career variables with CA approximately one and half standard deviations below the average and CO and CDSE approximately three quarters of a standard deviation below the average. The IP scores are in line with the sample average. This cluster is labeled "not prepared" indicating students who are not hopeful and appear to lack the adaptability and confidence needed to navigate the career landscape.

The fifth cluster has 43 participants and appears to have the students most psychologically prepared to join work force. This cluster is characterized by IP scores that are one standard deviation lower than the sample average and career variables that are all one standard deviation above. This cluster is called "very comfortable and highly prepared."

Cluster six is the second smallest cluster with 22 participants. It is characterized by nearly average scores on the career related scales and an IP score that is one standard 
deviation above the mean. This cluster is labeled "impostor" because the scores on the impostor phenomenon scales were highest of all the clusters and the scores on all of the other measures were near the sample mean.

\section{Comparison of Clusters on Dependent Variables}

Chi-square tests showed no significant differences between clusters based upon the environmental background (urban, suburban, or rural) of the student $X^{2}(10, N=228)$ $=8.55, p=.575$. There was a significant difference between clusters on the variable educational aspirations $X^{2}(10, \mathrm{~N}=228)=11.43, p=.044$. Post hoc analysis using an adjusted Bonferroni value indicated that in cluster 3 there was a lower than expected number of students who are interested in attaining a graduate degree. There was a significant difference between clusters on major decision status $X^{2}(10, N=228)=19.53$, $p=.002$. Post hoc analysis using an adjusted Bonferroni value indicated that in cluster 1 the number of students who have chosen a major was lower than expected.

Multivariate analysis of variance (MANOVA) was used to determine if there was a difference between the clusters on the racial identity subscales of the MMBI. The assumption of homogeneity of variance-covariances matrices was violated as assessed by Box's test of equality of covariance matrices $(p<.001)$. Given the violation of this assumption, Pillai's Trace was used to measure the overall group effect. There was a significant overall cluster group effect $F(35,1100.00)=2.55, p<.001$, Pillai's Trace

$=.38$, partial eta $^{2}=.08$. Follow-up univariate analysis of variance (ANOVAs) indicated that the clusters differed on the Central subscale $F(5,222)=2.44, p<.05$; the Private Regard subscale $F(5,222)=10.44, p<.001$; the Public Regard subscale $F(5,222)=$ $3.27, p<.05$; the Assimilation subscale $F(5,222)=2.30, p<.05$; the Humanist subscale 
$F(5,222)=4.43, p<.001$; and the Minority subscale $F(5,222)=2.77, p<.05$. There was not a significant difference between clusters on the Nationalist subscale $F(5,222)=$ $1.37, p=.237$

Since the equality of variances assumption was violated, the cluster means for the subscale Private Regard were compared using the Games-Howell post hoc test. Post hoc comparisons showed that the mean for Cluster $4(M=5.61, S D=1.09)$ was significantly less than the means from Cluster $6(M=6.70, S D=.44)$, Cluster $5(M=6.74, S D=.43)$, Cluster $3(M=6.37, S D=.71)$ and Cluster $2(M=6.31, S D=.72)$. The equality of variances assumption was violated on the Assimilation subscale as well. Post hoc analysis using Games-Howell indicated that the mean from Cluster $4(M=4.5, S D=.88)$ was significantly less than the means from Cluster $5(M=5.04, S D=.69)$ and Cluster 6 $(M=5.19, S D=.81)$.

Post hoc analysis using the Hochberg's GT 2 test indicated that on the subscale Public Regard the mean of Cluster $6(M=3.97, S D=1.23)$ is significantly greater than the mean of Cluster $1(M=2.81, S D=.78)$; on the Humanist subscale the mean Cluster 4 $(M=4.72, S D=.82)$ is significantly less than that of Cluster $2(M=5.34, S D=.70)$, Cluster 5(M=5.23, SD=.73) and Cluster $6(M=5.40, S D=.90)$.

ANOVAS were also conducted on the demographic variables age $F(5,222)=.86$, $p=.512$; mother's educational attainment $F(5,221)=.49, p=.79$; family income $F(5$, $202)=1.31, p=.26$; and academic year in school $F(5,222)=.40, p=.85$ and there were no significant differences observed across clusters. The variable father's educational attainment violated the assumption of homogeneity of variances, so Welch's F was used to determine statistical significance. There were no significant differences between the 
clusters on the variable father's educational attainment, Welch's $F(5,59.51)=1.90, p$ $=.11$.

The bivariate correlations for all study variables are presented in Table 1 . The subscale Private Regard significantly corelated with CA $r(226)=.453 p<.001$, with $\operatorname{CO} r(226)=.303,<.001$, and $\operatorname{CDSE} r(226)=.354 p<.001$. The Humanist subscale significantly correlated with CA $r(226)=.243, p<001$ and CDSE $r(226)=.260, p<.001$. It is important to note the Humanist subscale displayed low reliability $(\alpha=.62)$. The Oppressed Minority scale significantly correlated with IP $r(226)=.213, p<.001$. 


\section{CHAPTER 5}

\section{DISCUSSION}

This study aimed to explore Black college men's beliefs about their career preparedness and identify the characteristics of those who felt prepared to engage in the process of choosing and embarking on a career and those who did not. The researcher collected students' responses to instruments that measured Career Adaptability, Career Optimism, Career Decision Making Self-Efficacy, Impostor Phenomenon, and Racial Identity. Cluster analysis was then used to create profiles within the sample which signified different levels of the students' beliefs about their readiness to choose a fulfilling career after undergraduate school. The profiles that developed from the clustering procedure were then compared to each other based upon Racial Identity measures, socioeconomic status, age, year in school, environmental background, mother's educational attainment, father's educational attainment, educational aspirations, and whether the student had chosen a major. First this chapter will explore the relevance of the data observed. Then the connection to past research as well possibilities for future research will be discussed followed by implications for practice. Finally, limitations of the study will be shared.

One goal of creating profiles was to identify groups of students at the extremes of the measured variables and then ascertain how they might be identifiable on U.S. campuses. With this information faculty and student affairs staff can better understand and address the specific needs of students as they identify educational and career goals and prepare to pursue future plans. Students within the profiles will have unique needs, 
strengths, and barriers to success. It is also important to note that these measures do not assess static constructs, but instead address malleable phenomena that can be improved over time. Findings suggest that there could be distinct profiles within the Black male college student population that represent different levels of self-beliefs in their ability to successfully select and navigate a chosen career path. The results of the cluster analysis identified six distinct profiles: (1) impostor with low optimism and agency, (2) highly prepared impostor, (3) comfortable, (4) not prepared, (5) very comfortable and highly prepared, and (6) impostor. As shown in Figure 1, the profiles show a range of preparedness and impostor feelings with groups of students who reported a high level of impostor feelings and both high (Cluster 2) and low (Cluster 1) levels of preparedness to a low level of impostor feelings and high levels of preparedness (Cluster 5). Clusters 2, 5, 4 and 1 are characterized by students who scored at the highest and lowest levels of differentiation for the ranges for the clustering variables, thereby indicating those who feel they are most and least prepared for their career journeys. The details of the clusters will be expounded upon in the next section. Additionally, comparisons of the clusters based upon racial identity yielded significant and conflicting results and will be discussed below along with the results from comparisons based on the other observed variables.

\section{Cluster Profiles}

Participants' demographic data were observed to identify possible statistically significant results that would add to the profiles of the observed clusters and help ascribe identifiers that could help assign students to a particular profile. Analysis yielded only two significant results for the demographic variables. Cluster 3 had a lower than expected number of students who aspire to attend graduate school. A lower focus on graduate 
school is consistent with students with moderate scores on the career variables and a mean score on the IP scale that was lower than the sample average. Cluster 1 had a lowerthan-expected number of students who have not chosen a major which is somewhat congruent with the cluster's profile. This cluster has the lowest scores of all the clusters on CO and CDSE and has a relatively high IP score compared to the sample average. Lacking both optimism and the confidence to successfully navigate the career process are consistent with having indecision related to choosing a major (Rottinghaus et al., 2005). The results from this sample indicated that there were not significant differences between profile groups for socioeconomic status, environmental background, parents' educational attainment, age, or year in school.

Cluster 5 represented the ideal group with regard to perceived career preparedness and comfort in their current academic setting. This group, labeled "very comfortable and highly prepared," scored at the highest range for all of the career constructs and at the lowest range for the impostor phenomenon. This profile represents students who believe that they have what they need to successfully negotiate the career process and they feel comfortable in the current academic environment. Black male students' comfort levels are being inferred by their low IP scores and may be promising as most of the study participants attended PWIs and are very likely to pursue career within predominantly White environments. Racial identity measures for students in this cluster indicate that their Black identity is a central part of their self-concept. In addition, they hold the Black race in high esteem, believe that other groups do as well, and believe it's important to assimilate into the mainstream culture. This group does not appear to have a conflict relating to being Black and participating in predominantly White environments, which is 
especially significant given the highly racialized nature of the U.S. popular culture as it has become more tense, polarized, and divided on issues of race within the past decade.

Like Cluster 5, results from Cluster 2 showed a profile of students who feel prepared to successfully pursue their careers, but unlike Cluster 5 demonstrated high impostor scores in comparison to the other clusters. The Centrality racial identity subscale scores for Cluster 2 indicated that race is less important to their identity than that of the other clusters and their Private Regard scores indicate that they feel the least positive about their Black identity in comparison to the other clusters. This cluster also had the lowest score for the Nationalist ideology, indicating that they place the needs of Africans Americans as a group at a lower importance than the other clusters. Scores on the Humanist subscale were the second highest indicating a higher focus on recognizing commonalities across racial groups. It is important to note that this scale had low internal consistency thereby reducing the significance of this finding $(\alpha=.62)$.

In comparison to Cluster 5, Cluster 2 indicated having fewer positive feelings towards the Black racial group. Cluster 2 had the lowest Centrality scores, the second lowest Private Regard scores, and the lowest Nationalist scores out of all the clusters in the study. While their Centrality scores indicate that race is less central to their identity, their Private Regard and Nationalist scores indicate that they hold Black people and their own membership in the Black racial group in the lowest esteem compared to the students in the other clusters. The Nationalist scores indicate that the students in Cluster 2 place the needs of the Black community of lower importance than the students in the other clusters. These racial identity subscale scores could indicate that the polarizing role of race in U.S. society may have led these students to develop "self-hatred" feelings related 
to their racial identity. In contrast, the students in Cluster 5 who have positive feelings towards their Black racial identity have very low impostor feelings indicating that positive feelings about being Black may be a protective factor in general and specifically on a predominantly White campus.

The profiles for Cluster 1 and Cluster 4 show two groups of students who do not feel prepared for their careers. Cluster 1 had the lowest mean scores for CA and CDSE amongst all of the clusters and high IP scores. Cluster 1 is the smallest cluster $(n=14)$ at $6.1 \%$ of the sample and scored lower than all other clusters on Public regard and statistically significantly lower than Cluster 6 . This indicates that members of Cluster 1 , in comparison to the other clusters, think that other races see Blacks in lower esteem in comparison to the perceptions held by the Black men in the other clusters about how Blacks are perceived by other races. Cluster 1 is characterized by students who feel like impostors, do not feel prepared to choose and pursue a career, and do believe that other racial groups hold Black people their racial identity in high esteem in comparison to the other clusters. They also scored the highest on Centrality, indicating that their Black racial identity is a key component of their self-perception. The low Public regard scores evidenced in Cluster 1, combined with attending a predominantly White campus, may be contributing to their high impostor phenomenon scores as similarly suggested for Cluster 2. The label of "self-hatred" is less applicable as the group had the highest scores on the Nationalist and Centrality subscales, which denotes that being Black plays a significant role in their identity and they place a priority on supporting the needs of the Black community. 
Analysis also indicated that Cluster 1 had a lower number of students than expected who had not chosen a major. The low CO and CDSE scores and the lower number of students have not chosen a major are somewhat in line with research that shows lower optimism and self-efficacy correlate with lower satisfaction with academic major (McIlveen, Beccaria, \& Burton, 2013). While dissatisfaction with academic major and not choosing a major are not the same, they both indicate a lack of conviction towards the future which could be associated with levels of optimism and confidence.

Cluster 4 is also a profile of interest as it represents students who may especially benefit from additional support regarding career development. This group had average impostor feelings and low scores on all the career variables especially CA as compared to the sample averages. This was the only cluster with CA scores at one standard deviation below the mean in this sample. Cluster 4 had the highest number of statistically significant findings related to the racial identity variables. This group's score on the Assimilationist subscale was lower than all of the other clusters and statistically significantly lower than that of Cluster 6 . This indicated that members of this cluster had the weakest endorsement of the Assimilationist ideology, which believes in attempting to fit into the mainstream culture as much as possible. Cluster 4 was also significantly lower than all clusters on the Private Regard subscale, denoting they held the lowest esteem for other Blacks and their own inclusion in the Black race. Additionally, Cluster 4 had nearly the lowest scores on the Humanist subscale, which measures how much an individual focuses on the commonalities between people. The racial identity subscales contradict each other somewhat as this group does not endorse the common traits of all people or 
believe in assimilating into the mainstream culture but holds the most negative view of Black people among all the clusters.

In addition to the creation of the profiles, correlations were analyzed between the racial identity subscales and the career measures across the entire sample and findings indicate the presence of statistically significant associations. An important finding was the positive relationship between Private Regard and CA, CO, and CDSE. This suggests that the more positive Black male students feel towards their racial identity the more comfortable they feel towards their ability to choose their career. These overall correlational results were pronounced for Cluster 5, which had the highest score on the Private Regard subscale and along with high scores on CA, CO, CDSE, and low IP scores. The Humanist subscale had low, but significant positive correlations, with CA and CDSE. This association was observed in Cluster 2 and Cluster 5 as they ranked second and third, respectively, amongst all clusters and had the highest scores on CA, CO, and CDSE. Similarly, Cluster 2 and Cluster 5 ranked third and second on the Humanist subscale, respectively, on the Assimilationist subscale. There was not a statistically significant relationship between the Assimilationist subscale and the careerrelated constructs, but both the clusters ranked high on these subscales which focus on connecting with others outside of the Black community.

\section{Relationship of the Findings to Prior Research}

\section{Career Adaptability}

This was the first time that CA was used on an exclusively Black Male population. The internal consistency reliability estimate for CA was similar to previous 
studies with a Cronbach's alpha $=.80$ (Buyukgoze-Kavas, 2015; Rottinghaus, Day, \& Borgen, 2005). CA had positive significant correlations with CDSE and CO and an insignificant slightly negative correlation with IP. Neureiter et al. (2017) studied IP and CA in Austrian college students and observed a significant positive correlation. It should be noted that Neureiter et al. used the German version of the Career Adapt Abilities Scale (international form 2.0; Johnston et al., 2013; Savickas \& Porfeli, 2012) to measure CA instead of the CA scale in the Career Futures Inventory. The significant positive correlation between CA and the Racial Identity subscale Private Regard is important because it suggests that $\mathrm{CA}$ increases as Black men place a higher esteem on their own racial identity. This relationship was strongest in Cluster 5 where CA was high and Private Regard was ranked the highest and Cluster 2 in which CA was low and Private Regard was ranked the lowest.

\section{Career Optimism}

This was the first time that $\mathrm{CO}$ was used on an exclusively Black Male population. The internal consistency reliability estimate for $\mathrm{CO}$ was similar to previous studies with Cronbach's alpha $=.83$ (Rottinghaus, Day, \& Borgen, 2005). CO had significant positive correlations with CDSE and CA and a significant negative correlation with IP. The relationship between CO and CDSE was in line with a previous study conducted on Philippine undergraduates (Garcia et al, 2015). CO had a significant positive correlation with Private regard across the sample suggesting that $\mathrm{CO}$ increases as Black men place a higher esteem on their racial identity. This association was present in Cluster 5 which had the highest scores for Private Regard. It appears that this association was not present in Cluster 2 which demonstrated Private Regard scores that were the 
second lowest of all the clusters. But it should be noted that the range between Private Regard scores is small and there was not a statistically significant difference between Cluster 2 and Cluster 5. CO scores tended to be at one end of the range or the other as 2 clusters scored at one standard deviation above the mean, one scored approximately two thirds below the mean, and one cluster was one and a half standard deviations below the mean. The relationship between $\mathrm{CO}$ and IP suggests that efforts aimed at validating and boosting both the comfort level and confidence of Black male college students may lead toward increases in $\mathrm{CO}$ as IP decreases. Evidence for the efficacy of this intervention was observed in a study of CO and CDSE in Philippine undergraduates which showed that teacher and parental support appeared to have a positive impact on CO with CDSE being a moderator suggesting that $\mathrm{CO}$ increased as students gained more confidence (Garcia et al., 2015).

\section{Career Decision Making Self-Efficacy}

CDSE has been measured on Black college student samples in the past (Chaney, Hammond, Betz, \& Multon 2007). The internal consistency reliability estimate for this study was similar to previous studies with Cronbach's alpha $=.94$ (Betz, Hammond, \& Multon, 2005; Bounds, 2016). CDSE had significant positive correlations with CA, CO, and Private Regard across the sample, suggesting that CDSE increases as Black men place a higher esteem on their racial identity. This relationship was only observed in Cluster 5 which had the highest scores for Private Regard of all the clusters. Like CO, CDSE scores were more often at the ends of the sample range. Two clusters had mean scores one standard deviation above the sample mean and one cluster had a mean score approximately one standard deviation below the sample mean and one cluster with a 
mean score one and a half standard deviations below the sample mean. The correlation of $\mathrm{CO}$ and CDSE across these four clusters could indicate a causal relationship as suggested by results from Garcia et al. (2015). This is more support for universities to engage with Black male students in ways that build confidence.

\section{Impostor Phenomenon}

Impostor Phenomenon has been studied in Black college populations on several occasions over the past decade (Austin, Clar, Ross, \& Taylor, 2009; Bernard, Hoggard, Neblett, 2018; Cokley, Mcclain, Enciso, \& Martinez, 2012,). IP was negatively correlated with CA, and CDSE and had statistically significant negative correlation with CO. IP was significantly negatively correlated with the racial identity subscale Oppressed Minority across the sample, suggesting students who endorse impostor feelings may also feel it is important to identify with minority groups. The cluster IP mean scores also showed a tendency to place at the ends of the range with three clusters having IP scores approximately one standard deviation above the sample mean and one cluster with an IP mean score one standard deviation below the sample mean. IP is positively associated with minority status stress (Cokley, Mcclain, Enciso, \& Martinez, 2012), suggesting that the students in the sample may also experience distress related to their racial identity.

The scores of the clusters with high IP scores have different, and somewhat conflicting, racial identity subscales. Cluster 2 endorsed low Centrality, Private Regard, and Nationalist scores, suggesting they hold their racial identity in low esteem and place lower importance on the needs of the Black community in comparison to the students in other clusters. This attitude towards their racial identity could lead to internal conflict in a

predominantly White environment. Cluster 6, which also endorsed high IP scores, had the 
highest mean scores for Public Regard, Assimilationist, Humanist, and Oppressed Minority. These results suggest that in comparison to the other clusters, Cluster 6 places a high value on fitting into the mainstream, seeing the commonalities in all people, connecting with other oppressed minority groups, and believes that other groups think positively about Black people. Their scores on the racial identity measures would suggest more comfort being in a predominantly White environment. This could also indicate that the discomfort implied by the high IP scores is less associated with race and may be associated with another factor.

In contrast to the racial identity scores for Cluster 2, Cluster 1 has the highest Centrality scores, has the lowest scores for Public Regard, second lowest scores for Assimilationist, lowest Humanist scores, and highest Nationalist scores. This data suggests that students in this cluster both place a higher esteem on their Black racial identity than students in other clusters and place the needs of the Black community higher than students in other clusters. Cluster 1's attitudes towards Black community may place them in conflict with their predominantly White environment as these students means scores for impostor phenomenon were high at one standard deviation from the sample mean.

Overall, IP was high for 83 students which is over one third of the total sample. They represent three different cluster profiles Cluster $1(n=14)$ which is below average and titled "Impostor with low optimism and career agency" Cluster $2(n=47)$ above average and titled "Highly prepared impostor", and Cluster $6(n=22)$ which is average and titled "Impostor." 


\section{Implications for Future Research}

The data from this study yielded identifiable profiles of Black men who represent different levels of perceived career preparedness but there were no statistically significant variables that could help identity these students without having them take the measures used to develop the clusters. There is other data that could have been collected which may have had more of an impact such as grade point average, whether or not students come from a single parent household, and how active they are in campus organizations. This study used a positivist quantitative methodology and used measures to approximate internal beliefs and attitudes towards careers but a qualitative study that explores these questions could be instrumental in providing a more detailed picture of students' feelings and experiences which could offer an enhanced understanding of the narrative that accompanies data from the present study. In addition, more specific questions related to career readiness that are more reflective of the students' experiences, could be explored. For example, researchers could examine questions such as "How did you develop your career ambitions?" "What gives you the confidence that you can achieve this goal." "Do you feel like you belong here and why do you feel that way?" "What role does race play on your perspective on your career goals and how you approach them?" "What scares you or makes you hesitant about pursuing your goals?" "What doubts do you have about being successful in the pursuit of your goals." The open-ended nature of qualitative inquiry could broaden the range of responses and the explore the nuances related to the topics measured in this study which are unique to individuals.

This study used the IP scale to capture the students' beliefs and attitudes towards how well that they fit in their current environment. Students comfort level could have 
also been assessed with the University Belonging Questionnaire (Slaten, Ellison, Deemer, Hughes, \& Shemwell, 2018), which measures students' feelings of belonging on a college campus.

\section{Implications for Practice}

The profiles developed from this study can be used by faculty and student affairs professionals to identify the career development needs of students. The data collected on the profiles were not robust enough to place students in a particular cluster groups simply based upon their demographic information; therefore, students would have to be assessed similarly to how they were in this study to learn of their strengths and weaknesses in relation to these constructs. The practice of using this combination of career assessments is practical as most students finished the surveys in under 20 minutes and the measures could be administered as part of the student academic advising component. These tools could also be administered by vocational staff within campus career centers but as many students do not utilize the services of their campus's career center a significant portion of the population would not benefit from these tools. Using them as part of the formal academic advising process could prove to be diagnostic and inform advisers on what services could be most helpful for individual students. This could also be part of outreach platform for student organizations administered by staff from the career center.

This study focused on Black men, but all organizations centered on identities like race, gender, or culture as well fraternities and sororities might have an interest in receiving a career workshop that involves administering similar measures as part of a larger intervention. The Black Male Initiative is an example of an organization who could benefit from this type of pairing as their role on campus is to support Black men as they 
progress towards graduation. Implementing interventions like this might represent a shift in the emphasis that institutions place on career planning because, as mentioned, career services are optional and not used by a significant portion of students. An intervention that is part of a university-based initiative may be particularly beneficial for younger undergraduates as first year student are less likely to seek help (Dyson \& Renk, 2006). Similarly, students with low CDSE are less likely to seek counseling (Tirpak \& Schlosser, 2015), which suggests that they may be hesitant to seek career support as well.

\section{Research Limitations}

The profiles developed from the study are informative but there are several limitations which may have had an impact on the results. Of the 228 students who participated in this study 104 were from one mid-southern urban PWI institution, which calls into question how representative this sample can be of the greater Black male college population. This also skews the geographic representation of the study towards students from the Midwest/Southern region of the country. Another limitation is the nature of the recruiting process. A significant number of the students were contacted via their participation in their campus's Black Male Initiative program. These are organizations on campus created to support the academic progress of Black men, but they only represent a percentage of the Black men on campus. The criteria used to determine inclusion into the group could have skewed the data collected in this study.

\section{Conclusion}

The intent of the study was to explore the characteristics of Black male students who feel prepared to successfully negotiate the career process and the characteristics of those who do not. To that end the study was successful. Several profiles were developed 
that identified both students who feel confident about their futures and students who do not. This information can be used to develop interventions that help prepare students who are lacking in skills or confidence related to their career pursuits.

The findings from the present study addresses gaps in the extant literature related to Career Adaptability and Career Optimism and Black male college students.

Specifically, the association between $\mathrm{CA}$ and $\mathrm{CO}$ and the racial identity subscales of the MIBI provided data that indicated a positive correlation between the scales that assessed esteem for Black people. This is significant because it highlights the importance of Black men developing a positive self-image that is free of the negative stereotypes often associated with Black men and Black male achievement particularly in academic settings. This study looked at Black men and how they see the "self" in relation to career and race but is important to note that many of the obstacles that they will face in their careers will be structural. While we can help better prepare Black male students to navigate their careers, work must be done on the institutional level to reduce the obstacles that inhibit equity based on race. 
Table 1

Bivariate Correlations, Reliability Estimates, Means, and Standard Deviations

\begin{tabular}{|c|c|c|c|c|c|c|c|c|c|c|c|}
\hline \multirow{2}{*}{$N=228$} & \multirow{2}{*}{$\begin{array}{c}\text { Career } \\
\text { Adaptability }\end{array}$} & \multirow{2}{*}{$\begin{array}{c}\text { Career } \\
\text { Optimism }\end{array}$} & \multicolumn{3}{|c|}{ Impostor } & \multirow{2}{*}{$\begin{array}{l}\text { Private } \\
\text { Regard }\end{array}$} & \multirow{2}{*}{$\begin{array}{l}\text { Public } \\
\text { Regard }\end{array}$} & \multirow[b]{2}{*}{ Assimilationist } & \multicolumn{3}{|c|}{ Oppressed } \\
\hline & & & CDSE & Phenomenon & Centrality & & & & Humanist & Minority & Nationalist \\
\hline Career Adaptability & $(0.80)$ & & & & & & & & & & \\
\hline Career Optimism & $.504^{* *}$ & $(0.83)$ & & & & & & & & & \\
\hline CDSE & $.533^{* *}$ & $.680^{* *}$ & $(0.94)$ & & & & & & & & \\
\hline Impostor Phenomenon & -0.074 & $-.353^{* *}$ & -0.097 & $(0.92)$ & & & & & & & \\
\hline Centrality & $.201^{* *}$ & 0.079 & 0.125 & 0.035 & (0.74) & & & & & & \\
\hline Private Regard & $.435^{* *}$ & $.303^{* *}$ & $.354^{* *}$ & -0.066 & $.466 * *$ & $(0.82)$ & & & & & \\
\hline Public Regard & $.136^{*}$ & $.215^{* *}$ & $.197 * *$ & -0.048 & $-.201^{* *}$ & 0.022 & $(0.71)$ & & & & \\
\hline Assimilationist & $.181^{* *}$ & $.200^{* *}$ & $.215^{* *}$ & 0.104 & $-.209 * *$ & 0.084 & $.282^{* *}$ & $(0.72)$ & & & \\
\hline Humanist & $.243^{* *}$ & $.182^{* *}$ & $.260^{* *}$ & 0.105 & $-.219 * *$ & $.220^{* *}$ & $.245 * *$ & $.533 * *$ & 0.62 & & \\
\hline Oppressed Minority & $.172^{* *}$ & -0.012 & $.137^{*}$ & $.213^{* *}$ & 0.002 & $.148^{*}$ & $.186^{* *}$ & $.530 * *$ & $.456 * *$ & $(0.77)$ & \\
\hline Nationalist & 0.094 & -0.087 & 0.09 & 0.069 & $.469 * *$ & $.218^{* *}$ & -0.047 & $-.222 * *$ & $-.313^{* *}$ & -0.054 & $(0.77)$ \\
\hline M & 61.07 & 3.56 & 4.01 & 95.87 & 5.11 & 6.34 & 3.52 & 4.84 & 5.11 & 4.89 & 4.14 \\
\hline SD & 15.54 & 0.62 & 0.47 & 15.54 & 1.07 & 0.80 & 0.96 & 0.89 & 0.78 & 0.92 & 0.92 \\
\hline
\end{tabular}

Note. Cronbach's alpha on the diagonal

** Correlation is significant at the 0.01 level (2-tailed)

* Correlation is significant at the 0.05 level (2-tailed) 
Table 2

MIBI Subscale Means

\begin{tabular}{|c|c|c|c|c|}
\hline MIBI Subscales & $M$ & SD & Skewness & Kurtosis \\
\hline \multicolumn{5}{|l|}{ Central } \\
\hline Cluster 1 & 5.72 & 1.05 & -0.87 & -0.50 \\
\hline Cluster 5 & 5.35 & 1.07 & -0.06 & -1.07 \\
\hline Cluster 6 & 5.26 & 1.44 & -1.14 & 0.75 \\
\hline Cluster 4 & 4.74 & 0.87 & -0.10 & -0.78 \\
\hline Cluster 3 & 5.04 & 0.94 & -0.45 & -0.25 \\
\hline Cluster 2 & 5.02 & 1.12 & -0.58 & 0.15 \\
\hline Total Sample & 5.11 & 1.07 & -0.42 & -0.14 \\
\hline \multicolumn{5}{|l|}{ Private Regard } \\
\hline Cluster 5 & 6.74 & 0.43 & -2.77 & 9.37 \\
\hline Cluster 6 & 6.70 & 0.44 & -1.16 & -0.10 \\
\hline Cluster 1 & 6.39 & 0.90 & -1.78 & 1.96 \\
\hline Cluster 3 & 6.37 & 0.71 & -1.75 & 3.50 \\
\hline Cluster 2 & 6.31 & 0.72 & -1.31 & 1.24 \\
\hline Cluster 4 & 5.61 & 1.09 & -0.75 & -0.31 \\
\hline Total Sample & 6.34 & 0.80 & -1.70 & 2.70 \\
\hline \multicolumn{5}{|l|}{ Public Regard } \\
\hline Cluster 6 & 3.97 & 1.23 & 0.49 & 0.14 \\
\hline Cluster 5 & 3.64 & 0.95 & -0.18 & -0.29 \\
\hline Cluster 3 & 3.56 & 0.84 & -0.85 & 0.17 \\
\hline Cluster 2 & 3.51 & 0.93 & -0.53 & 0.09 \\
\hline Cluster 4 & 3.27 & 0.98 & -0.85 & 0.17 \\
\hline Cluster 1 & 2.81 & 0.78 & -0.60 & -0.69 \\
\hline Total Sample & 3.52 & 0.96 & -0.21 & 0.47 \\
\hline \multicolumn{5}{|l|}{ Assimilationist } \\
\hline Cluster 6 & 5.19 & 0.81 & -0.56 & -0.29 \\
\hline Cluster 5 & 5.04 & 0.69 & -1.02 & 2.02 \\
\hline Cluster 2 & 5.01 & 1.05 & -0.44 & 0.14 \\
\hline Cluster 3 & 4.72 & 0.84 & -0.48 & 0.83 \\
\hline Cluster 1 & 4.60 & 0.98 & 0.39 & -0.50 \\
\hline Cluster 4 & 4.50 & 0.88 & 0.24 & 1.25 \\
\hline Total Sample & 4.84 & 0.89 & -0.33 & 0.16 \\
\hline \multicolumn{5}{|l|}{ Humanist } \\
\hline Cluster 6 & 5.40 & 0.90 & -0.51 & 0.49 \\
\hline Cluster 2 & 5.34 & 0.70 & 0.28 & -0.10 \\
\hline Cluster 5 & 5.23 & 0.73 & 0.09 & -0.46 \\
\hline Cluster 3 & 5.08 & 0.74 & 0.11 & -0.55 \\
\hline Cluster 4 & 4.72 & 0.82 & -0.69 & 1.81 \\
\hline Cluster 1 & 4.69 & 0.59 & -0.24 & -0.31 \\
\hline Total Sample & 5.11 & 0.78 & -0.10 & 0.30 \\
\hline \multicolumn{5}{|c|}{ Oppressed Minority } \\
\hline Cluster 6 & 5.26 & 1.19 & -0.33 & -0.31 \\
\hline Cluster 2 & 5.19 & 0.85 & 0.09 & -0.50 \\
\hline Cluster 1 & 4.87 & 0.79 & -0.75 & 1.12 \\
\hline Cluster 5 & 4.84 & 0.92 & -0.32 & -0.40 \\
\hline Cluster 3 & 4.75 & 0.81 & 0.18 & 0.25 \\
\hline Cluster 4 & 4.61 & 0.93 & -0.38 & 0.54 \\
\hline Total Sample & 4.89 & 0.92 & -0.06 & 0.10 \\
\hline \multicolumn{5}{|l|}{ Nationalist } \\
\hline Cluster 1 & 4.66 & 1.06 & 0.27 & -0.66 \\
\hline Cluster 6 & 4.28 & 0.96 & 0.33 & -1.44 \\
\hline Cluster 5 & 4.19 & 0.94 & -0.27 & -0.05 \\
\hline Cluster 3 & 4.11 & 0.82 & 0.05 & 0.98 \\
\hline Cluster 4 & 4.01 & 0.87 & -0.48 & 0.71 \\
\hline Cluster 2 & 4.00 & 1.01 & 0.84 & 0.59 \\
\hline Total Sample & 4.14 & 0.92 & 0.21 & 0.16 \\
\hline
\end{tabular}


Table 3

Final Six-Cluster Mean Centers

\begin{tabular}{|lcccc|}
\hline \multicolumn{1}{|c}{ Variable } & M & SD & Skewness & Kurtosis \\
\hline Cluster 1 & & & & \\
$\quad$ Impostor Phenomenon & 77.21 & 10.79 & -0.08 & -1.31 \\
$\quad$ Career Optimism & 2.47 & 0.35 & 0.16 & -0.01 \\
$\quad$ Career Adaptability & 4.02 & 0.33 & -0.28 & -1.58 \\
$\quad$ Career Decision Making Self-Efficacy & 68.43 & 7.62 & -6.53 & 1.91 \\
\hline Cluster 2 & & & & \\
$\quad$ Impostor Phenomenon & 76.83 & 8.35 & 0.62 & 0.06 \\
Career Optimism & 3.32 & 0.36 & 0.12 & -0.89 \\
Career Adaptability & 3.93 & 0.27 & 0.11 & 0.13 \\
Career Decision Making Self-Efficacy & 99.13 & 9.26 & 0.56 & -0.07 \\
\hline Cluster 3 & & & & \\
Impostor Phenomenon & 50.71 & 7.94 & -0.31 & -0.33 \\
Career Optimism & 3.64 & 0.37 & -0.89 & 0.38 \\
Career Adaptability & 3.99 & 0.29 & 0.35 & 0.36 \\
Career Decision Making Self-Efficacy & 91.54 & 8.65 & -0.51 & 0.27 \\
\hline Cluster 4 & & & & \\
Impostor Phenomenon & 62.09 & 7.71 & 0.47 & 0.47 \\
Career Optimism & 3.08 & 0.31 & 1.12 & 0.40 \\
Career Adaptability & 3.28 & 0.25 & 0.45 & -0.25 \\
Career Decision Making Self-Efficacy & 81.06 & 9.76 & -0.75 & 0.77 \\
\hline Cluster 5 & & & & \\
Impostor Phenomenon & 46.37 & 8.71 & -0.30 & -0.96 \\
Career Optimism & 4.30 & 0.38 & 0.15 & -0.82 \\
Career Adaptability & 4.44 & 0.30 & 0.08 & -0.58 \\
Career Decision Making Self-Efficacy & 113.28 & 8.38 & -0.07 & -1.28 \\
\hline Cluster 6 & & & & \\
Impostor Phenomenon & 76.27 & 10.53 & 0.81 & -0.05 \\
Career Optimism & 4.17 & 0.31 & 0.90 & 1.40 \\
Career Adaptability & 4.55 & 0.30 & 0.19 & -1.15 \\
Career Decision Making Self-Efficacy & 108.64 & 11.16 & -0.03 & -0.78 \\
\hline
\end{tabular}


Table 4

Cluster Sizes and Labels for the Six-Cluster Solution

\begin{tabular}{|ccl}
\hline Cluster & N & Description Label \\
\hline 1 & 14 & Impostor with low optimism and career agency \\
2 & 47 & Highly prepared impostor \\
3 & 68 & Comfortable \\
4 & 34 & Not prepared \\
5 & 43 & Very comfortable and highly prepared \\
6 & 22 & Impostor \\
\hline Total & 228 & \\
\hline
\end{tabular}


Table 5

\section{Cluster Comparisons}

\begin{tabular}{|lll}
\hline Analysis & Variable & Outcome \\
\hline Chi Square & Environmental Background & No Differences \\
& Educational Aspiration & Cluster 3: Lower than expected number of students aspiring to earn a graduate degree \\
& Chose a Major (Yes or No) & Cluster 1: Lower than expected number of students who have chosen a major \\
& & \\
\hline ANOVA & Age & No Differences \\
& Mother's Educational Attainment & No Differences \\
& Father's Educational Attainment & No Differences \\
& Family Income & No Differences \\
& Academic Year in School & No Differences \\
& & \\
\hline RANOVA & Racial Identity Subscales & No Differences \\
& Central & $4<1,2,3,5,6$ \\
& Private Regard & $1<6$ \\
& Public Regard & $4<6$ \\
& Assimilation & $4<2,5,6$ \\
Humanist & No Differences \\
Minority & No Differences \\
Nationalist &
\end{tabular}

Note. All differences are significant at the .05 level

Table 6 
Participant Institution

\begin{tabular}{llcc}
\hline College or University & Location & Frequency & Percent \\
\hline Baruch College & New York, NY & 6 & 2.6 \\
Bethune-Cookman University & Daytona Beach, FL & 1 & 0.4 \\
DePaul University & Chicago, IL & 1 & 0.4 \\
Edward Waters College & Jacksonville, FL & 1 & 0.4 \\
Florida A\&M University & Tallahasee, FL & 3 & 1.3 \\
John Jay College of Criminal Justice & New York, NY & 5 & 2.2 \\
Lousiana State University & Baton Rouge, LA & 5 & 2.2 \\
Medgar Evers College & Brooklyn, NY & 2 & 0.9 \\
Missouri State University & Springfield, MO & 1 & 0.4 \\
North Carolina A\&T & Greensboro, NC & 1 & 0.4 \\
Northern Illinois University & Dekalb, IL & 22 & 9.6 \\
Northern Kentucky University & Highland Heights, KY & 2 & 0.9 \\
Ohio State University & Columbus, OH & 1 & 0.4 \\
Queens College & Queens, NY & 3 & 1.3 \\
Saint Louis University & St. Louis, MO & 1 & 0.4 \\
Tennessee Technology University & Cookeville, TN & 1 & 0.4 \\
The University of Southern Mississippi & Hattiesburg, MS & 1 & 0.4 \\
University of Louisville & Louisville, KY & 104 & 45.6 \\
University of Maryland & College Park, MD & 1 & 0.4 \\
University of Missouri & Columbia, MO & 26 & 11.4 \\
Washington University in St. Louis & St. Louis, MO & 40 & 17.5 \\
\hline
\end{tabular}

Figure 1 


\section{6-Cluster Solution}

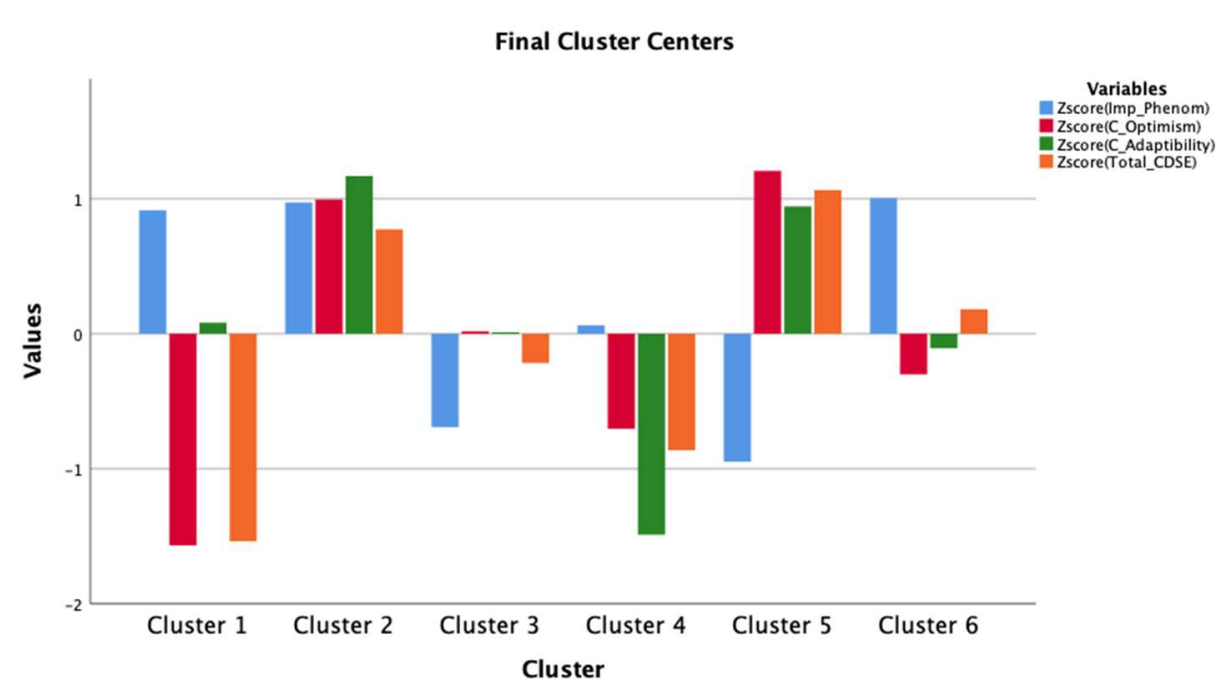

Figure 2 
7-Cluster Solution

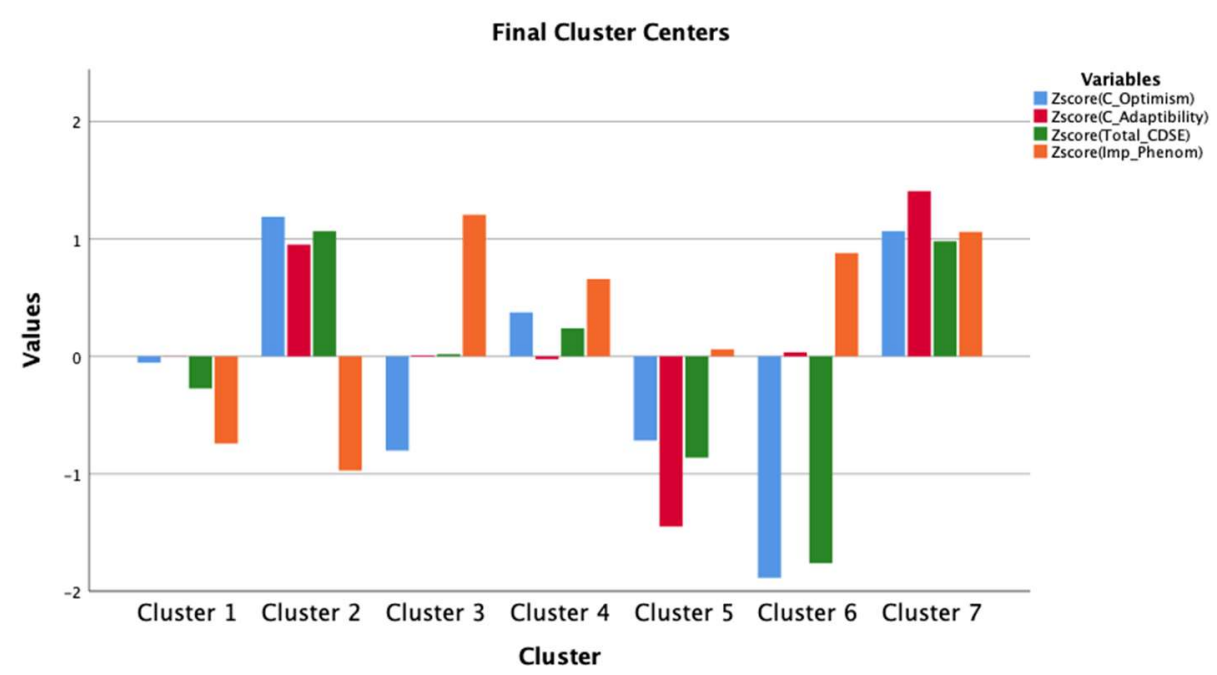


Figure 3

5-Cluster Solution

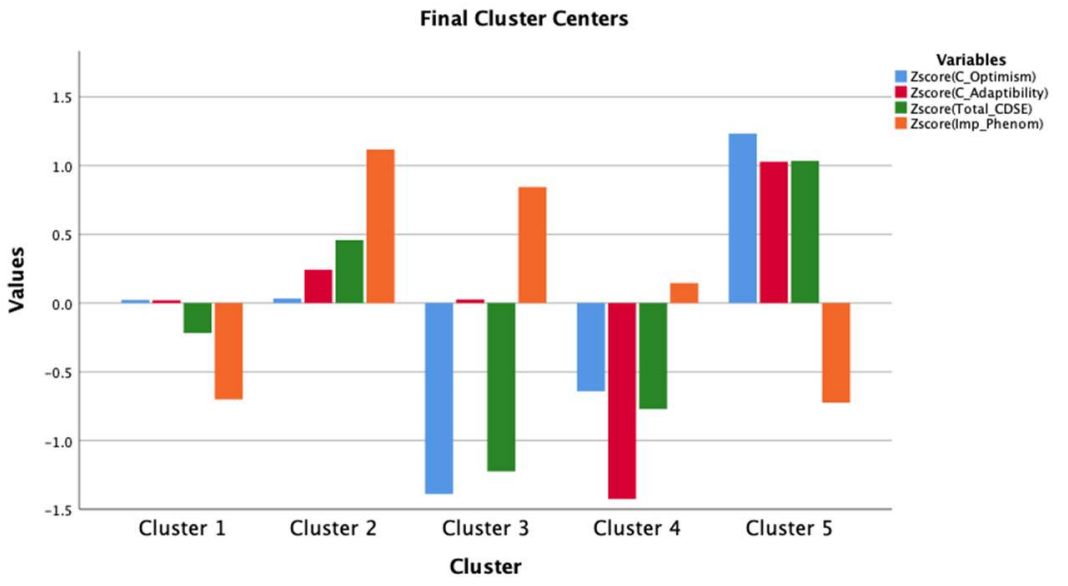




\section{Figure 4}

\section{4-Cluster Solution}

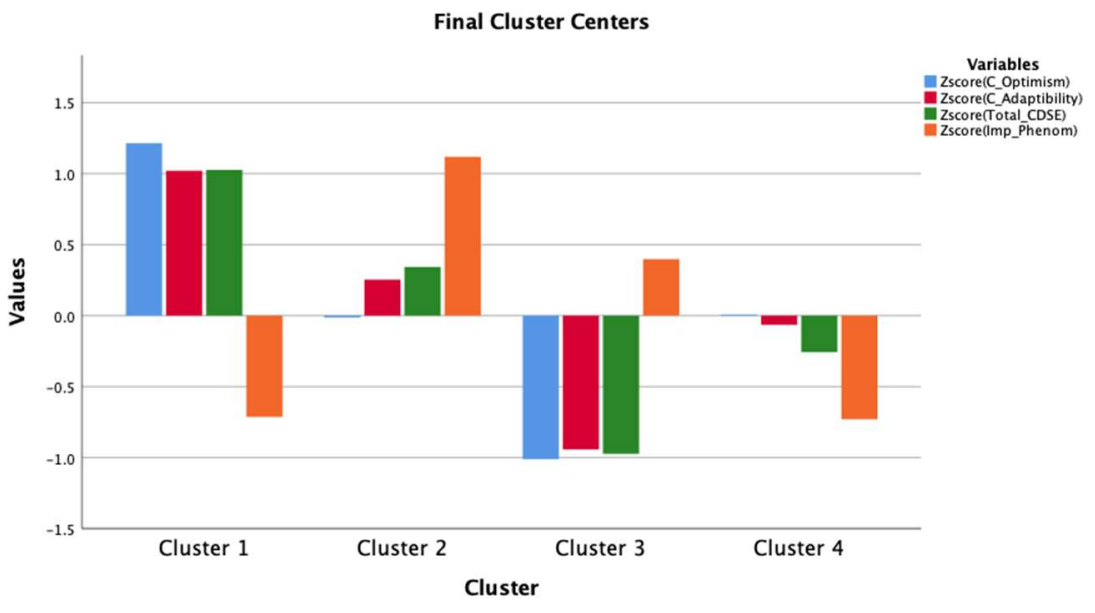


Figure 5

3-Cluster Solution

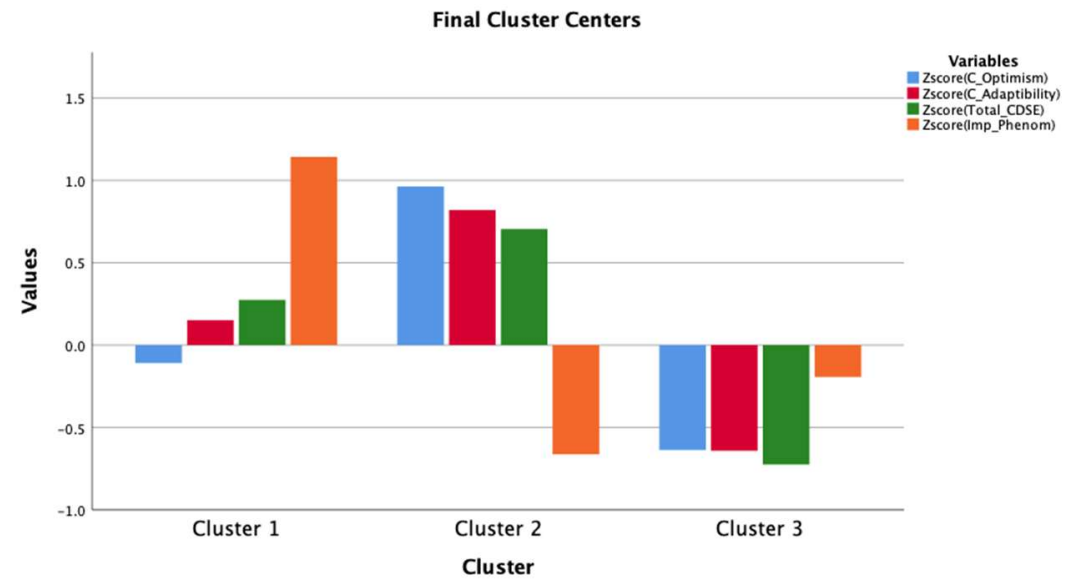


Figure 6

2-Cluster Solution

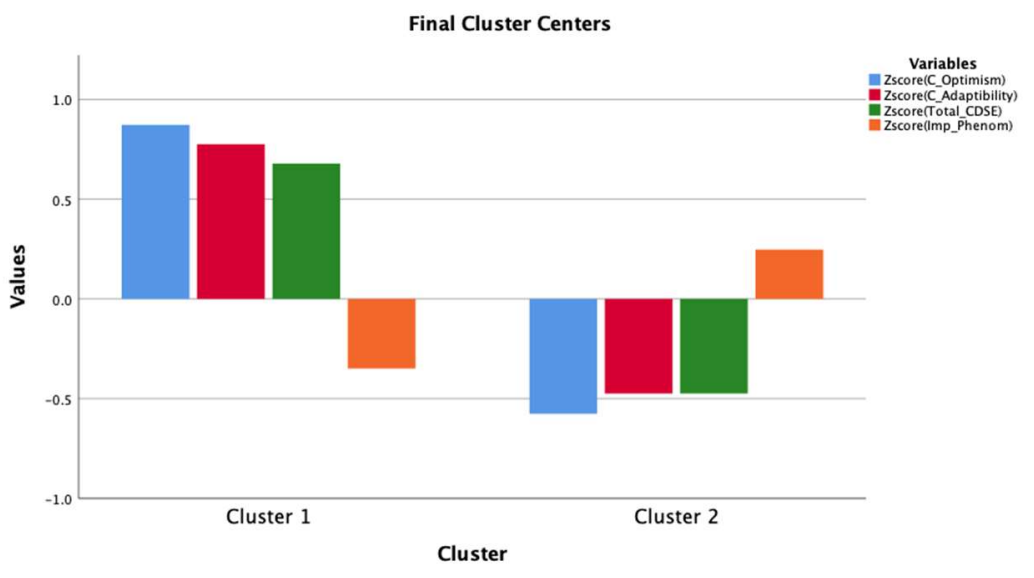




\section{Figure 7}

Participants by Region of the Country

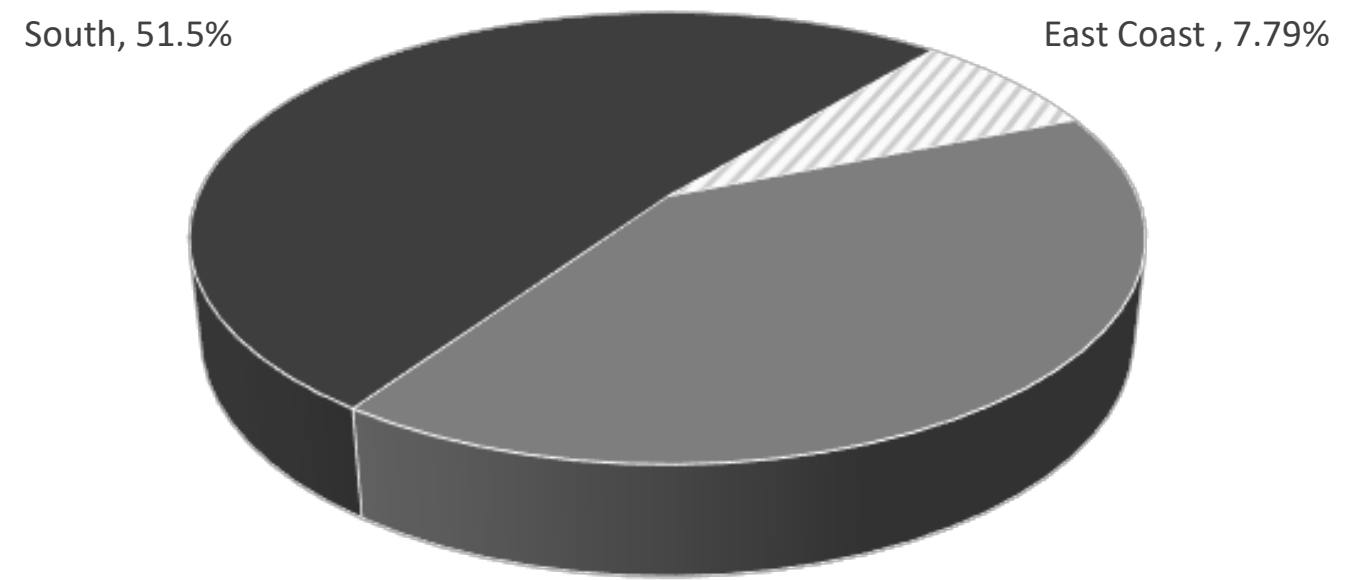

Midwest , 40.7\% 


\section{References}

American Dental Association. (2020) Racial and Ethnic Mix of the Dentist Workforce in the U.S. https://www.ada.org/ /media/ADA/Science\%20and\%20Research/HPI/Files/HPIg raphic_0421_1.pdf?la=en

American Bar Association. (2020). ABA Profile of the Legal Profession. https://www.americanbar.org/content/dam/aba/administrative/news/2020/07/potlp 2020.pdf

Association of American Medical College. (2019). Diversity in Medicine: Facts and Figures 2019. https://www.aamc.org/data-reports/workforce/report/diversitymedicine-facts-and-figures-2019

Allen, W. R. (1992). The color of success: African American college student outcomes at predominantly White and historically Black public colleges and universities. Harvard Educational Review, 62, 26-44.

Aspinwall, L. G., Richter, L., \& Hoffman, R. R., III. (2001). Understanding how optimism works: An examination of optimists' adaptive moderation of belief and behavior. In E. C. Chang (Ed.), Optimism \& pessimism (pp. 217-238).

Washington, DC: American Psychological Association.

Aud, S., Fox, M., \& KewalRamani, A. (2010). Status and trends in the education of racial and ethnic groups (NCES 2010-015). U.S. Department of Education, National Center for Education Statistics. Washington, DC: U.S. Government Printing Office.

Austin, C. Y. (2010). Perceived factors that influence career decision self-efficacy and 
engineering related goal intentions of African American high school students. Career and Technical Education Research, 35, 119-135.

Austin, C. C., Clark, E. M., Ross, M. J., \& Taylor, M. J. (2009). Impostorism as a mediator between survivor guilt and depression in a sample of African American college students. College Student Journal, 43(4, PtA), 1094-1109.

Bandura, A. (1977). Self-efficacy: Toward a unifying theory of behavioral change. Psychological Review, 84, 191-215.

Bandura, A. (1986). Social foundations of thought and action: A social cognitive theory. Englewood Cliffs, NJ: Prentice Hall.

Bandura, A. (1997). Self-efficacy: The exercise of control. New York, NY: Freeman.

Barrett, I. C., Cervero, R. M., \& Johnson-Bailey, J. (2004). The career development of Black human resource developers in the United States. Human Resource Development International, 7(1), 85-100.

Becker, B. E., \& Luthar, S. S. (2002). Social-emotional factors affecting achievement outcomes among disadvantaged students: Closing the achievement gap. Educational Psychologist, 37, 197-214.

Bernard, D. L., Hoggard, L. S., \& Neblett, E. W., Jr. (2018). Racial discrimination, racial identity, and impostor phenomenon: A profile approach. Cultural Diversity and Ethnic Minority Psychology, 24(1), 51-61.

Betz, N. E., Klein, K., \& Taylor, K. (1996). Evaluation of a short form of the Career Decision- Making Self-Efficacy Scale. Journal of Career Assessment, 4, 47-57.

Betz, N., \& Luzzo, D. (1996). Career assessment and the Career Decision-Making SelfEfficacy Scale. Journal of Career Assessment, 4, 313-328. 
Betz, N. E., \& Hackett, G. (1981). The relationship of career-related self-efficacy expectations to perceived career options in college women and men. Journal of Counseling Psychology, 28(5), 399-410.

Blustein, D. L., Chaves, A. P., Diemer, M. a., Gallagher, L. A., Marshall, K. G., Sirin, S., \& Bhati, K. S. (2002). Voices of the forgotten half: The role of social class in the school-to-work transition. Journal of Counseling Psychology, 49, 311-323.

Blustein, D. L., Devenis, L. E., \& Kidney, B. A. (1989). Relationship between the identity formation process and career development. Journal of Counseling Psychology, 36(2), 196-202.

Borgen, F. H., \& Barnett, D. C. (1987). Applying cluster analysis in counseling psychology research. Journal of Counseling Psychology, 34(4), 456-468. http://dx.doi.org/10.1037/0022-0167.34.4.456

Bores-Rangel,E., Church, A.T., Szendre, D., \& Reeves, C. (1990). Self-efficacy in relation to occupational consideration and academic performance in high school equivalency students. Journal of Counseling Psychology, 37, 407-418.

Bounds, P.S. (2017), Contextual Factors Related to African American Adolescent Career Development. The Career Development Quarterly, 65: 131-144.

Brown, C., Darden, E.E., Shelton, M.L., \& Dipoto, M.C. (1999). Career exploration and self-efficacy of high school students: Are there urban/suburban differences? Journal of Career Assessment, 7(3), 227-237.

Bullock-Yowell, E., Andrews, L., \& Buzzetta, M. E. (2011). Explaining career decisionmaking self-efficacy: Personality, cognitions, and cultural mistrust. Career Development Quarterly, 59(5), 400-411. 
Buyukgoze-Kavas, A. (2016). Predicting career adaptability from positive psychological traits. The Career Development Quarterly, 64(2), 114-125.

Buyukgoze-Kavas, A., Duffy, R. D., \& Douglass, R. P. (2015). Exploring links between career adaptability, work volition, and well-being among Turkish students. Journal of Vocational Behavior, 90, 122-13.

Byars-Winston, A. (2010). The vocational significance of Black identity: Cultural formulation approach to career assessment and career counseling. Journal of Career Development, 37, 441-464.

Campbell, D. (1998, August). Optimism: The leadership edge. [Paper presented at the American Psychological Association annual convention, San Francisco.]

Carver, C. S., \& Scheier, M. F. (1981). Attention and self-regulation: A control-theory approach to human behavior. New York: Springer-Verlag.

Carver, C. S., \& Scheier, M. F. (2001). Optimism, pessimism, and self-regulation. In E. C. Chang (Ed.), Optimism \& pessimism (pp. 31-51). Washington, DC: American Psychological Association.

Chaney, D., Hammond, M. S., Betz, N. E., \& Multon, K. D. (2007). The Reliability and Factor Structure of the Career Decision Self-Efficacy Scale-SF With African Americans. Journal of Career Assessment, 15(2), 194-205.

Chrisman, S. M., Pieper, W. A., Clance, P. R., Holland, C. L., \& Glickauf- Hughes, C. (1995). Validation of the Clance imposter phenomenon scale. Journal of Personality Assessment, 65, 456-467. 
Clance, P. R., Dingman, D., Riviere, S. L., \& Stober, D. R. (1995). Imposter phenomenon in an interpersonal/social context: Origins and treatment. Women \& Therapy, 16, $79-96$.

Clance, P. R, (1985). The impostor phenomenon: Overcoming the fear that haunts your success. Atlanta: Peachtree.

Clance, P. R., \& Imes, S. A. (1978). The impostor phenomenon in high-achieving women: Dynamics and therapeutic intervention. Psychotherapy: Theory, Research, \& Practice, 15, 241-247.

Clark, K. B., \& Clark, M. K. (1939). Segregation as a factor in the racial identification of Negro pre-school children. Journal of Experimental Education, 8, 161-163.

Cokley, K. (2000a). An investigation of academic self-concept and its relationship to academic achievement in African American college students. Journal of Black Psychology, 26(2), 148-164.

Cokley, K. (2002). The impact of college racial composition on African American students' aca- demic self-concept: A replication and extension. Journal of Negro Education, 71, 288-296.

Cokley, K., Smith, L., Bernard, D., Hurst, A., Jackson, S., Stone, S., . . Roberts, D. (2017). Impostor feelings as a moderator and mediator of the relationship between perceived discrimination and mental health among racial/ethnic minority college students. Journal of Counseling Psychology, 64(2), 141-154.

Cokley, K., McClain, S., Enciso, A., \& Martinez, M. (2013). An examination of the impact of minority status stress and impostor feelings on the mental health of 
diverse ethnic minority college students. Journal of Multicultural Counseling and Development, 41, 82-95.

Costa, P. T., Jr., \& McCrae, R. R. (1992). The NEO Personality Inventory (NEO PI-R) and NEO Five-Factor Inventory (NEO-FFI) professional manual. Odessa, FL: Psychological Assessment Resources.

Cozzarelli, C, \& Major, B. (1990). Exploring the validity of the impostor phenomenon. Journal of Social and Clinical Psychology, 9, 401-417.

Creed, P. A., Patton, W., \& Bartrum, D. (2002). Multidimensional properties of the LOT-R: Effects of optimism and pessimism on career and well-being related variables in adolescents. Journal of Career Assessment, 10, 42-61.

Crites, J.O. (1978). Career maturity inventory (1st ed.). Monterey, CA: CTB/McGraw- Hill

Cross, W. E., Jr. (1971). The Negro-to-Black conversion experience. Black World, 20, $13-27$.

Cross, W. E., Jr., Parham, T. A., \& Helms, J. E. (1991). The stages of Black identity development: Nigrescence models. In R. L. Jones (Ed.), Black psychology (p. 319-338). Cobb \& Henry Publishers.

Cross, W. E., \& Cross, T. B. (2008). Theory, research, and models. In S. M. Quintana \& C. McKown (Eds.), Handbook of race, racism, and the developing child (pp. 154181). John Wiley \& Sons, Inc..

Dyson, R., \& Renk, K. (2006). Freshmen Adaptation to University Life: Depressive Symptoms, Stress, and Coping. Journal of Clinical Psychology, 62(10), 12311244. 
Eva, N., Newman, A., Jiang, Z., \& Brouwer, M. (2020). Career optimism: a systematic review and agenda for future research. Journal of Vocational Behavior, 116, 1-18.

Everitt, B., Landau, S., Leese, M., \& Stahl, D. (2011). Cluster analysis. (5th ed.) Wiley.

Ewing, K. M., Richardson, T. Q., James-Myers, L., \& Russell, R. K. (1996). The relationship between racial identity attitudes, worldview, and African American graduate students' experience of the imposter phenomenon. Journal of Black Psychology, 22, 53-66.

Fleming, J. (1984). Blacks in college. San Francisco: Jossey-Bass.

Gaines, S. O., Jr., \& Reed, E. S. (1995). Prejudice: From Allport to DuBois. American Psychologist, 50(2), 96-103.

Gaines, S. O., \& Reed, E. S. (1994). Two social psychologies of prejudice: Gordon W. Allport, W. E. B. DuBois and the legacy of Booker T. Washington. Journal of Black Psychology, 20(1), 8-28.

Garcia, P. R. J. M., Restubog, S. L. D., Bordia, P., Bordia, S., \& Roxas, R. E. O. (2015). Career optimism: THE roles of contextual support and career decision-making self-efficacy. Journal of Vocational Behavior, 88, 10-18.

Gerardi, S. (1990). Academic self-concept as a predictor of academic success among minority and low-socioeconomic status students. Journal of College Student Development, 31, 402-407.

Gordon, A. D. (1999). Classification (Second Edition). Chapman \& Hall, London

Gore, P. A., Jr. (2000). Cluster analysis. In H. E. A. Tinsley \& S. D. Brown (Eds.), Handbook of applied multivariate statistics and mathematical modeling (pp. 297-321). 
Graham, S. (1997). Using attribution theory to understand social and academic motivation in African American youth. Educational Psychologist, 32, 21-34.

Guan, Y., Deng, H., Sun, J., Wang, Y., Cai, Z., Ye, L., ... Li, Y. (2013). Career adaptability, job search self-efficacy and outcomes: A three-wave investigation among Chinese university graduates. Journal of Vocational Behavior, 83, 561570.

Guan, Y., Guo, Y., Bond, M. H., Cai, Z., Zhou, X., Xu, J., ... Ye, L. (2014). New job market entrants' future work self, career adaptability and job search outcomes: Examining mediating and moderating models. Journal of Vocational Behavior, $85,136-145$.

Guerino, P., Harrison, P. M., \& Sabol, W. (2011). Prisoners in 2010. Washington, DC: Bureau of Justice Statistics.

Gushue, G. V., \& Whitson, M. L. (2006). The relationship among support, ethnic identity, career decision self-efficacy, and outcome expectations in African American high school students: Applying social cognitive career theory. Journal of Career Development, 33(2), 112-124. doi:10.1177/0894845306293416

Hackett, G., \& Betz, N. E. (1981). A self-efficacy approach to the career development of women. Journal of Vocational Behavior, 18(3), 326-339.

Hair, J. F. \& Black W. C. (2000) Cluster Analysis. L. G. Grimm, \& P. R. Yarnold, (Eds.) Reading and Understanding More Multivariate Statistics. (pp. 147-205). Washington, D.C.: American Psychological Association.

Hall, D., \& Mirvis, P. (1995). The new career contract: Developing the whole person at midlife and beyond. Journal of Vocational Behavior, 47, 269-289. 
HSC Health Tracking Survey, 2008

Helms, J. E. (1990). The measurement of Black racial identity attitudes. In J. E. Helms (Ed.), Black and White racial identity: Theory, research, and practice (pp. 33-47). New York: Greenwood Press.

Henning, K., Ey, S., \& Shaw, D. (1998). Perfectionism, the imposter phenomenon and psychological adjustment in medical, dental, nursing and pharmacy students. Medical Education, 52, 456-464.

Hoffman, K., Llagas, C., \& Snyder, T. D. (2003). Status and trends in the education of Blacks. Washington, D.C.: US Department of Education, National Center for Educational Statistics.

Holland, J. L. (1997). Making vocational choices: A theory of vocational personalities and work environments (3rd ed.). Odessa, FL: Psychological Assessment Resources.

Holmes, S. W, Kertay, L., Adamson, L. B., Holland, C. L., \& Clance, P. R. (1993). Measuring the impostor phenomenon: A comparison of the Clance and Harvey IP scales. Journal of Personality Assessment, 60, 48-59.

Hope, E. C., Chavous, T. M., Jagers, R. J., \& Sellers, R. M. (2013). Connecting self-esteem and achievement diversity in academic identification and disidentification patterns among black college students. American Educational Research Journal, 50, 1122 1151. http://dx.doi .org/10.3102/0002831213500333

Horowitz, R. E. (1939). Racial aspects of self-identification in nursery school children. The Journal of Psychology: Interdisciplinary and Applied, 7, 91-99. 
Johnston, J. A. (1999). Occupational Daydreams Inventory. Columbia: University of Missouri.

Jackson, B. (1976). Black identity development. In L. H. P. Golubchick (Ed), Urban, social, and educational issues (pp.158-164). Dubuque, IA: Kendall/Hunt.

Johnston, C. S., Luciano, E. C., Maggiori, C., Ruch, W., \& Rossier, J. (2013). Validation of the German version of the Career Adapt-Abilities Scale and its relation to orientations to happiness and work stress. Journal of Vocational Behavior, 83, 295-304.

Kaplan, D. S., Peck, B. M., \& Kaplan, H. B. (1997). Decomposing the academic failuredropout relationship: A longitudinal analysis. Journal of Educational Research, 90, 331-343.

Kenny, M. E., Blustein, D. L., Chaves, A., Grossman, J. M., \& Gallagher, L. A. (2003). The role of perceived barriers and relational support in the educational and vocational lives of urban high school students. Journal of Counseling Psychology, $50,142-155$.

Kluemper, D.H., Little, L.M., \& DeGroot, T. (2009). State or trait: Effects of state optimism on job-related outcomes. Journal of Organizational Behavior, 30, 209231.

Ladany, N., Melincoff, D. S., Constantine, M. G., \& Love, R. (1997). At-risk urban high school students' commitment to career choices. Journal of Counseling \& Development, 76, 45-52.

Leary, M. R., Patton, K. M., Orlando, A. E., \& Wagoner Funk, W. (2000). The impostor phenomenon: Self-perceptions, reflected appraisals, and interpersonal strategies. 
Journal of Personality, 68, 725-756.

Lent, R. W. (2020). Career development and counseling: A social cognitive framework. In S. D. Brown \& R. Lent (Eds.), Career development and counseling: Putting theory and research to work (3rd ed., pp. 129-163). New York: Wiley.

Lent, R. W. (2013). Career-life preparedness: Revisiting career planning and adjustment in the new workplace. The Career Development Quarterly, 61(1), 2-14.

Lent, R. W., Brown, S. D., \& Hackett, G. (1994). Toward a unifying social cognitive theory of career and academic interest, choice, and performance. Journal of Vocational Behavior, 45, 79-122.

Lucas, J. L., \& Wanberg, C. R. (1995). Personality correlates of Jones' three-dimensional model of career indecision. Journal of Career Assessment, 3, 315-329.

Maher, E. J., \& Kroska, A. (2002). Social status determinants of control in individuals' accounts of their mental illness. Social Science and Medicine, 55, 949-961.

Major, B., Spencer, S., Schmader, T., Wolfe, C., \& Crocker, J. (1998). Coping with negative stereotypes about intellectual performance: The role of psychological disengagement. Personality and Social Psychology Bulletin, 24, 34-50. http://dx.doi.org/10.1177/0146167298241003

Marko, K. W., \& Savickas, M. L. (1998). Effectiveness of a career time perspective intervention. Journal of Vocational Behavior, 52, 106-119.

McClain, S., Beasley, S. T., Jones, B., Awosogba, O., Jackson, S., \& Cokley, K. (2016). An examination of the impact of racial and ethnic identity, impostor feelings, and minority status stress on the mental health of Black college students. Journal of Multicultural Counseling and Development, 44, 101-117. 
McIlveen, P., Beccaria, G., \& Burton, L.J. (2013). Beyond conscientiousness: Career optimism and satisfaction with academic major. Journal of Vocational Behavior, $83,229-236$.

McMillian, M. M., Carr, M., Hodnett, G., \& Campbell, F. A. (2015). A longitudinal study of academic identification among African American males and females. The Journal of Black Psychology. Advance online publication. http://dx.doi.org/10.1177/0095798415603845

National Science Foundation. (2015). Women, Minorities, and Persons with Disabilities in Science and Engineering. https://www.nsf.gov/statistics/2017/nsf17310/digest/occupation/blacks.cfm

Neureiter, M., \& Traut-Mattausch, E. (2017). Two sides of the career resources coin: Career adaptability resources and the impostor phenomenon. Journal of Vocational Behavior, 98, 56-69.

O’Brien, K.M., Bikos, L.H., Epstein, K.L., Flores, L.Y., Dukstein, R.D., \& Kamatuka, N.A. (2000). Enhancing the career decision-making self-efficacy of upward bound students. Journal of Career Development, 26(4), 277-293.

Osborne, J. W. (1995). Academics, self-esteem, and race: A look at the underlying assumptions of the disidentification hypothesis. Personality and Social Psychology Bulletin, 21, 449-455.

Osborne, J. W. (1997). Race and academic dis- identification. Journal of Educational Psychology, 89, 728-735.

Parham, T. A., \& Helms, J. E. (1981). The influence of Black students' racial identity attitudes on preference for counselor's race. Journal of Counseling Psychology, 
$28,250-258$.

Peteet, B. J., Brown, C. M., Lige, Q. M., \& Lanaway, D. A. (2015). Impostorism is associated with greater psychological distress and lower self-esteem for African American students. Current Psychology, 34, 154-163.

Peteet, B., Montgomery, L., \& Weekes, J. C. (2015). Predictors of imposter phenomenon among talented ethnic minority undergraduate students. The Journal of Negro Education, 84, 175-186.

Peterson, S., \& delMas, R. C. (2001). Effects of career-decision-making self-efficacy and degree utility on student persistence: A path analytic study. Journal of College Student Retention: Research, Theory, and Practice, 3, 285-299.

Ponterotto, J. G., \& Wise, S. L. (1987). Construct validity study of the racial identity attitude scale. Journal of Counseling Psychology, 34(2), 218-223.

Porter, J., \& Washington, R. (1979). Black Identity and Self-Esteem: A Review of Studies of Black Self-Concept, 1968-1978. Annual Review of Sociology, 5, 5374.

Post Secondary National Policy Institue. (2020, June). Factsheets. https://pnpi.org/african-american-students/

Pouyaud, J., Vignoli, E., Dosnon, O., \& Lallemand, N. (2012). Career adapt-abilities scale-France form: Psychometric properties and relationships to anxiety and motivation. Journal of Vocational Behavior, 80, 692-697.

Reynolds, W. M. (1988). Measurement of academic self-concept in college students. Journal of Personality Assessment, 52, 223-240.

Rottinghaus, P. J., Buelow, K. L., Matyja, A., \& Schneider, M. R. (2012). The career 
futures inventory-revised: Measuring dimensions of career adaptability. Journal of Career Assessment, 20(2), 123-139. doi:10.1177/1069072711420849

Rottinghaus, P. J., Day, S. X., \& Borgen, F. H. (2005). The career futures inventory: A measure of career-related adaptability and optimism. Journal of Career Assessment, 13(1), 3-24. doi:10.1177/1069072704270271

Rottinghaus, P. J., Jenkins, N., \& Jantzer, A. M. (2009). Relation of depression and affectivity to career decision status and self-efficacy in college students. Journal of Career Assessment, 17(3), 271-285. doi:10.1177/1069072708330463

Rosenberg, M., and Simmons, R. G. (1971). Black and White Self-Esteem: The Urban School Child, American Sociological Association, Washington, DC.

Rossier, J., Zecca, G., Stauffer, S. D., Maggiori, C., \& Dauwalder, J. -P. (2012). Career Adapt-Abilities Scale in a French-speaking Swiss sample: Psychometric properties and relationships to personality and work engagement. Journal of Vocational Behavior, 80, 734-743.

Rowley, S. J., Sellers, R. M., Chavous, T. M., \& Smith, M. A. (1998). The relationship between racial identity and self-esteem in african american college and high school students. Journal of Personality and Social Psychology, 74(3), 715-724. doi:10.1037/0022-3514.74.3.715

Sonnak, C, \& Towell, T. (2000). The impostor phenomenon in British university students: Relationships between self-esteem, mental health, parental rearing style, and socioeconomic status. Personality and Individual Differences, 31, 863-874. 
Savickas, M. L. (2020). Career construction theory and counseling model. In S. D. Brown \& R. Lent (Eds.), Career development and counseling: Putting theory and research to work (3rd ed., pp. 165-199). New York: Wiley.

Savickas, M. L. (2013). Career construction theory and counseling model. In S.D. Brown \& R. W. Lent (Eds.), Career development and counseling: Putting theory and research to work ( $3^{\text {rd }}$ ed., pp. 165-199). New York: Wiley.

Savickas, M. L. (1997). Career adaptability: An integrative construct for life-span, lifespace theory. Career Development Quarterly, 45, 247-259.

Savickas, M. L. (2005). The theory and practice of career construction. In S. D. Brown, \& R. W. Lent (Eds.), Career development and counselling: Putting theory and research to work (pp. 42-70).

Savickas, M. L., \& Porfeli, E. J. (2012). Career Adapt-Abilities Scale: Construction, reliability, and measurement equivalence across 13 countries. Journal of Vocational Behavior, 80, 661-673.

Savickas, M. L., Nota, L., Rossier, J., Dauwalder, J., Duarte, M. E., Guichard, J., et al. (2009). Life-designing: A paradigm for career construction in the 21 st century. Journal of Vocational Behavior, 75, 239-250.

Savickas, M., Silling, S. M., \& Schwartz, S. (1984). Time perspective in vocational maturity and career decision making. Journal of Vocational Behavior, 25, 258269.

Schott Foundation. (2015). Black Lives Matter: The Schott 50 State Report on Public Education and Black Males. http://blackboysreport.org/bbreport2015.pdf 
Schunk, D. H., \& Ertmer, P. A. (2000). Self-regulation and academic learning: Selfefficacy enhancing interventions. In M. Boekaerts, P. R. Pintrich, \& M. Zeidner (Eds.), Handbook of self-regulation (pp. 631-649). Academic Press.

Seber, G. A. F. (1984). Multivariate observations. New York: Wiley.

Sellers, R. M., Rowley, S. A. J., Chavous, T. M., Shelton, J. N., \& Smith, M. A. (1997). Multidimensional inventory of black identity: A preliminary investigation of reliability and construct validity. Journal of Personality and Social Psychology, 73(4), 805-815. doi:10.1037/0022-3514.73.4.805

Sellers, R. M., Smith, M. A., Shelton, J. N., Rowley, S. A. J., \& Chavous, T. M. (1998). Multidimensional Model of Racial Identity: A Reconceptualization of African American Racial Identity. Personality and Social Psychology Review, 2(1), $18-$ 39.

Sellers, R. M. (1993). A call to arms for researchers studying racial identity. Journal of Black Psychology, 19, 327-332.

Shavelson, R. J. Hubenr, J. JH. \& Stanton, G. C. (1976) Self-concept: Validation of construct interpretations. Review of Educational Research, 46, 407-441.

Shavelson, R. J. \& Bolus, R. (1982) Self-concept: The interplay of theory and methods. Journal of Educational Psychology, 74, 3-17.

Slaten, C. D., Elison, Z. M., Deemer, E. D., Hughes, H. A., \& Shemwell, D. A. (2018). The development and validation of the University Belonging Questionnaire. Journal of Experimental Education, 86(4), 633-651 
Smith, Ryan, (2002). Race, gender, and authority in the workplace: Theory and research. Annual Review of Sociology, 28, 509-542.

Smith, Ryan. (2005). Do the determinants of promotion differ for white men versus women and minorities? An Exploration of Intersectionalism Through Sponsored and Contest Mobility Processes. American Behavioral Scientist, 48, 1182-1199.

Steele, C. (1992). Race and the schooling of African-Americans. Atlantic Monthly, 269(4), 68-78.

Strutton, D., \& Lumpkin, J. (1992). Relationship between optimism and coping strategies in the work environment. Psychological Reports, 71, 1179-1186.

Super, D. E. (1990). A life-span, life-space approach to career development. In D. Brown, L. Brooks, \& Associates (Eds.), Career choice and development: Applying contemporary theories to practice (2nd ed., pp. 197-261). San Francisco: Jossey-Bass.

Super, D. E., \& Kidd, J. M. (1979). Vocational maturity in adulthood: Toward turning a model into a measure. Journal of Vocational Behavior, 14, 255-270.

Super, D. E., \& Knasel, E. G. (1979). Specifications for a measure of career adaptability in young adults. Cambridge, UK: National Institute for Career Education and Counseling.

Super, D. E., \& Knasel, E. G. (1981). Career development in adulthood: Some theoretical problems and a possible solution. British Journal of Guidance and Counseling, 9, 194-201.

Super, D. E. (1955). The dimensions and measurement of vocational maturity. Teachers College Record, 57, 151-163. 
Swanson, J. L. (1992). Vocational behavior, 1989-1991: Life-span career development and reciprocal interaction of work and nonwork. Journal of Vocational Behavior, $41,101-161$.

Taylor, K., \& Popma, J. (1990). An examination of the relationships among career decision- making self-efficacy, career salience, locus of control, and vocational indecision. Journal of Vocational Behavior, 37, 17-31.

Taylor, K. M., \& Betz, N. E. (1983). Applications of self-efficacy theory to the understanding and treatment of career indecision. Journal of Vocational Behavior, 22, 63-81.

Terenzini, P. T., Pascarella, E. T., \& Blimling, G. S. (1996). Students' out-of-class experiences and their influence on learning and cognitive development: A literature review. Journal of College Student Development, 37, 149-162.

Terrell, F., \& Terrell, S. L. (1981). An inventory to measure cultural mistrust among Blacks. Western Journal of Black Studies, 3, 180-185.

Thomas, C. W. (1971) Boys No More: A Black Psychologists View of Community. Beverly Hills, CA: Glencoe.

Thompson, T., David, H., \& Davidson, J. (1998). Attributional and affective responses of impostors to academic success and failure outcomes. Personality and Individual Differences, 25, 381-396.

Tirpak, D. M., \& Schlosser, L. Z. (2015). Relationship between self-efficacy and counseling attitudes among first-year college students. Journal of College Counseling, 18(3), 209-221.

Tokar, D. M., Fisher, A. R., \& Subich, L. M. (1998). Personality and vocational behavior: 
A selected review of the literature, 1993-1997. Journal of Vocational Behavior, 53, 115-153.

Topping, M. E., \& Kinimel, E. B. (1985). The imposter phenomenon: Feeling phony. Academic Psychology Bulletin, 7, 213-226.

U.S News and World Report. (2021, April). 2021 Best National University Rankings. https://www.usnews.com/best-colleges/rankings/nationaluniversities?int=top_nav_National_Universities

U.S. Bureau of Labor Statistics. (2020). Current population survey. https://www.bls.gov/cps/cpsaat11.htm

U.S. Bureau of Labor Statistics. (2007). Current population survey.

U.S. Bureau of Labor Statistics. (2011). Current population survey.

Vandiver, B. J., Fhagen-Smith, P. E., Cokley, K. O., Cross, W. E., Jr., \& Worrell, F. C. (2001). Cross's nigrescence model: From theory to scale to theory. Journal of Multicultural Counseling and Development, 29(3), 174-200.

Van Laar, C. (2000). The paradox of low aca- demic achievement but high self-esteem in African American students: An attributional account. Educational Psychology Review, 12(1), 33-59.

Walker, J. V. III, \& Peterson, G. W. (2012). Career thoughts, indecision, and depression: Implications for mental health assessment in career counseling. Journal of Career Assessment, 20(4), 497-506

Wilson, George, Sakura-Lemessy, Ian, West, John, (1999). Reaching the top: racial differences in mobility paths to upper-tier occupations. Work Occup. 26, 165186. 
Wilson, Valeire. (2020, September) Racial disparities in income and poverty remain largely unchanged amid strong income growth in 2019, Economic Policy Institute. https://www.epi.org/blog/racial-disparities-in-income-and-povertyremain-largely-unchanged-amid-strong-income-growth-in-2019/

Witherspoon, K. M., Speight, S. L., \& Thomas, A. J. (1997). Racial identity attitudes, school achievement, and academic self-efficacy among African American high school students. Journal of Black Psychology, 23, 344-357.

Youssef, C.M., \& Luthans, F. (2007). Positive organizational behavior in the workplace the impact of hope, optimism, and resilience. Journal of Management, 33, 774800.

Zacher, H. (2015). Daily manifestations of career adaptability: Relationships with job and career outcomes. Journal of Vocational Behavior, 91, 76-86.

Zimmerman, B. J., \& Ringle, J. (1981). Effects of model persistence and statements of confidence on children's self-efficacy and problem solving. Journal of Educational Psychology, 73(4), 485-493. doi:10.1037/0022-0663.73.4.485 


\section{APPENDIX A}

\section{CDMSE-Short Form}

INSTRUCTIONS: For each statement below, please read carefully and indicate how much confidence you have that you could accomplish each of these tasks by marking your answer according to the key, Mark your answer by filling in the correct circle on the answer sheet.

$\begin{array}{ccccc}\text { NO CONFIDENCE } & \text { VERY LITTLE } & \text { MODERATE } & \text { MUCH } & \text { COMPLETE } \\ \text { AT ALL } & \text { CONFIDENCE } & \text { CONFIDENCE } & \text { CONFIDENCE } & \text { CONFIDENCE } \\ 1 & 2 & 3 & 4 & 5\end{array}$

Example: How much confidence do you have that you could:

a. Summarize the skills you have developed in the jobs you have held?

If your response was "Moderate Confidence," you would fill out the number 3 on the blank provided.

HOW MUCH CONFIDENCE DO YOU HAVE THAT YOU COULD:

1. Find information in the library about occupations you are interested in.

2. Select one major from a list of potential majors you are considering.

3. Make a plan of your goals for the next five years.

4. Determine the steps to take if you are having academic trouble with an aspect of your chosen major.

5. Accurately assess your abilities.

6. Select one occupation from a list of potential occupations you are considering.

7. Determine the steps you need to take to successfully complete your chosen major.

8. Persistently work at your major or career goal even when you get frustrated.

9. Determine what your ideal job would be.

10. Find out the employment trends for an occupation over the next ten years.

11. Choose a career that will fit your preferred lifestyle.

12. Prepare a good resume. 
13. Change majors if you did not like your first choice.

14. Decide what you value most in an occupation.

15. Find out about the average yearly earnings of people in an occupation.

16. Make a career decision and then not worry whether it was right or wrong.

$\begin{array}{ccccc}\text { NO CONFIDENCE } & \text { VERY LITTLE } & \text { MODERATE } & \text { MUCH } & \text { COMPLETE } \\ \text { AT ALL } & \text { CONFIDENCE } & \text { CONFIDENCE } & \text { CONFIDENCE } & \text { CONFIDENCE } \\ 1 & 2 & 3 & 4 & 5\end{array}$

HOW MUCH CONFIDENCE DO YOU HAVE THAT YOU COULD:

17. Change occupations if you are not satisfied with the one you enter.

18. Figure out what you are and are not ready to sacrifice to achieve your career goals.

19. Talk with a person already employed in a field you are interested in.

20. Choose a major or career that will fit your interests.

21. Identify employers, firms, and institutions relevant to your career possibilities.

22. Define the type of lifestyle you would like to live.

23. Find information about graduate or professional schools.

24. Successfully manage the job interview process.

choice.

25. Identify some reasonable major or career alternatives if you are unable to get your first

Copyright @2001, Nancy Betz \& Karen Taylor. Not to be used without permission. 


\author{
APPENDIX B \\ Career Futures Inventory \\ (c) 2000, 2008 Patrick J. Rottinghaus, Ph.D.
}

This questionnaire assesses critical factors for people considering career transitions. You will be asked a series of questions regarding your current thoughts and feelings about how you plan your career. Please answer the following items as honestly as you can. There are no right or wrong answers. Read each statement carefully, then use the following scale to indicate how strongly you agree or disagree with each statement:

\title{
$5=$ Strongly Agree \\ $4=$ Agree \\ $3=$ Neutral \\ $2=$ Disagree \\ $1=$ Strongly Disagree
}

1. I get excited when I think about my career

2. I am eager to pursue my career dreams

3. I am unsure of my future career success

4. Thinking about my career frustrates me

5. It is difficult to relate my abilities to a specific career plan

6. I understand my work-related interests

7. I do not understand job market trends

8. I can overcome potential barriers that may exist in my career

9. It is difficult for me to set career goals

10. I am not in control of my career success

11. I tend to bounce back when my career plans don't work out quite right

12. I am rarely in control of my career

13. Thinking about my career inspires me

14. My career success will be determined by my efforts 
15. I will definitely make the right decisions in my career

16. I enjoy trying new work-related tasks

17. I am good at adapting to new work settings

18. I can adapt to change in my career plans

19. It is hard to discover the right career

20. Others would say that I am adaptable to change in my career plans

21. I will adjust easily to shifting demands at work

22. I can adapt to change in the world of work

23. Planning my career is a natural activity

24. I am good at understanding job market trends

25. It is easy to see future employment trends

Career Optimism: 1, 2, 3, 4, 5, 6, 9, 13, 15, 19, and 23.

Career Adaptability: 8, 10, 11, 12, 14, 16, 17, 18, 20, 21, and 22.

Knowledge: 7, 24, and 25

The following items are reverse-scored: 3, 4, 5, 7, 9, 10, 12, and 19. 


\section{APPENDIX C}

\section{Clance IP Scale}

For each question, please circle the number that best indicates how true the statement is of you. It is best to give the first response that enters your mind rather than dwelling on each statement and thinking about it over and over.

1. I have often succeeded on a test or task even though I was afraid that I would not do well before I undertook the task.

12345 (not at all true) (rarely) (sometimes) (often) (very true)

2. I can give the impression that l'm more competent than I really am.

12345 (not at all true) (rarely) (sometimes) (often) (very true)

3. I avoid evaluations if possible and have a dread of others evaluating me.

12345 (not at all true) (rarely) (sometimes) (often) (very true)

4. When people praise me for something l've accomplished, I'm afraid I won't be able to live up to their expectations of me in the future.

12345 (not at all true) (rarely) (sometimes) (often) (very true)

5. I sometimes think I obtained my present position or gained my present success because I happened to be in the right place at the right time or knew the right people.

12345 (not at all true) (rarely) (sometimes) (often) (very true)

6. I'm afraid people important to me may find out that l'm not as capable as they think I am. 12345

(not at all true) (rarely) (sometimes) (often) (very true) 7. I tend to remember the incidents in which I have not done my best more than those times I have done my best.

12345 (not at all true) (rarely) (sometimes) (often) (very true) 
8. I rarely do a project or task as well as l'd like to do it.

12345 (not at all true) (rarely) (sometimes) (often) (very true)

9. Sometimes I feel or believe that my success in my life or in my job has been the result of some kind of error.

12345 (not at all true) (rarely) (sometimes) (often) (very true)

10. It's hard for me to accept compliments or praise about my intelligence or accomplishments. 12345

(not at all true) (rarely) (sometimes) (often) (very true)

11. At times, I feel my success has been due to some kind of luck.

12345 (not at all true) (rarely) (sometimes) (often) (very true)

12. I'm disappointed at times in my present accomplishments and think I should have accomplished much more. 12345

(not at all true) (rarely) (sometimes) (often) (very true)

13. Sometimes l'm afraid others will discover how much knowledge or ability I really lack.

12345 (not at all true) (rarely) (sometimes) (often) (very true)

14. I'm often afraid that I may fail at a new assignment or undertaking even though I generally do well at what I

attempt.

12345 (not at all true) (rarely) (sometimes) (often) (very true)

15. When l've succeeded at something and received recognition for my accomplishments, I have doubts that I can keep repeating that success.

12345 (not at all true) (rarely) (sometimes) (often) (very true)

16. If I receive a great deal of praise and recognition for something l've accomplished, I tend to discount the importance of what l've done. 
12345 (not at all true) (rarely) (sometimes) (often) (very true)

17. I often compare my ability to those around me and think they may be more intelligent than I am.

12345 (not at all true) (rarely) (sometimes) (often) (very true)

18. I often worry about not succeeding with a project or examination, even though others around me have considerable confidence that I will do well.

12345 (not at all true) (rarely) (sometimes) (often) (very true)

19. If I'm going to receive a promotion or gain recognition of some kind, I hesitate to tell others until it is an

accomplished fact.

12345 (not at all true) (rarely) (sometimes) (often) (very true)

20. I feel bad and discouraged if I'm not "the best" or at least "very special" in situations that involve achievement. 12345

(not at all true) (rarely) (sometimes) (often) (very true)

\section{Scoring the Impostor Test}

The Impostor Test was developed to help individuals determine whether or not they have IP characteristics and, if so, to what extent they are suffering.

After taking the Impostor Test, add together the numbers of the responses to each statement. If the total score is $\mathbf{4 0}$ or less, the respondent has few Impostor characteristics; if the score is between 41 and 60, the respondent has moderate IP experiences; a score between 61 and 80 means the respondent frequently has Impostor feelings; and a score higher than 80 means the respondent often has intense IP experiences. The higher the score, the more frequently and seriously the Impostor Phenomenon interferes in a person's life.

Note. From The Impostor Phenomenon: When Success Makes You Feel Like A Fake (pp. 20-22), by P.R. Clance, 1985, Toronto: Bantam Books. Copyright 1985 by Pauline Rose Clance, Ph.D., ABPP. Reprinted by permission. Do not reproduce without permission from Pauline Rose Clance, drpaulinerose@comcast.net, www.paulineroseclance.com. 


\section{The Multidimensional Model of Black Identity (MMBI)}

\begin{tabular}{|c|c|c|c|c|c|c|c|c|}
\hline & & $\begin{array}{l}\text { Strongly } \\
\text { Disagree }\end{array}$ & & & Neutral & & & $\begin{array}{r}\text { Strongly } \\
\text { Agree }\end{array}$ \\
\hline 1. & $\begin{array}{l}\text { Overall, being Black has very little to do with how I feel about } \\
\text { myself. }\end{array}$ & 1 & 2 & 3 & 4 & 5 & 6 & 7 \\
\hline 2. & $\begin{array}{l}\text { It is important for Black people to surround their children with } \\
\text { Black art, music and literature. }\end{array}$ & 1 & 2 & 3 & 4 & 5 & 6 & 7 \\
\hline 3. & Black people should not marry interracially. & 1 & 2 & 3 & 4 & 5 & 6 & 7 \\
\hline 4. & I feel good about Black people. & 1 & 2 & 3 & 4 & 5 & 6 & 7 \\
\hline 5. & Overall, Blacks are considered good by others. & 1 & 2 & 3 & 4 & 5 & 6 & 7 \\
\hline 6. & In general, being Black is an important part of my self-image. & 1 & 2 & 3 & 4 & 5 & 6 & 7 \\
\hline 7. & I am happy that I am Black. & 1 & 2 & 3 & 4 & 5 & 6 & 7 \\
\hline 8. & $\begin{array}{l}\text { I feel that Blacks have made major accomplishments and } \\
\text { advancements. }\end{array}$ & 1 & 2 & 3 & 4 & 5 & 6 & 7 \\
\hline 9. & My destiny is tied to the destiny of other Black people. & 1 & 2 & 3 & 4 & 5 & 6 & 7 \\
\hline 10. & $\begin{array}{l}\text { Blacks who espouse separatism are as racist as White people who } \\
\text { also espouse separatism. }\end{array}$ & 1 & 2 & 3 & 4 & 5 & 6 & 7 \\
\hline 11. & Blacks would be better off if they adopted Afrocentric values. & 1 & 2 & 3 & 4 & 5 & 6 & 7 \\
\hline 12. & $\begin{array}{l}\text { Black students are better off going to schools that are controlled } \\
\text { and organized by Blacks. }\end{array}$ & 1 & 2 & 3 & 4 & 5 & 6 & 7 \\
\hline 13. & $\begin{array}{l}\text { Being Black is unimportant to my sense of what kind of person I } \\
\text { am. }\end{array}$ & 1 & 2 & 3 & 4 & 5 & 6 & 7 \\
\hline 14. & $\begin{array}{l}\text { Black people must organize themselves into a separate Black } \\
\text { political force. }\end{array}$ & 1 & 2 & 3 & 4 & 5 & 6 & 7 \\
\hline 15. & In general, others respect Black people. & 1 & 2 & 3 & 4 & 5 & 6 & 7 \\
\hline 16. & $\begin{array}{l}\text { Whenever possible, Blacks should buy from other Black } \\
\text { businesses. }\end{array}$ & 1 & 2 & 3 & 4 & 5 & 6 & 7 \\
\hline 17. & $\begin{array}{l}\text { Most people consider Blacks, on the average, to be more } \\
\text { ineffective than other racial groups. }\end{array}$ & 1 & 2 & 3 & 4 & 5 & 6 & 7 \\
\hline 18. & $\begin{array}{l}\text { A sign of progress is that Blacks are in the mainstream of America } \\
\text { more than ever before. }\end{array}$ & 1 & 2 & 3 & 4 & 5 & 6 & 7 \\
\hline 19. & I have a strong sense of belonging to Black people. & 1 & 2 & 3 & 4 & 5 & 6 & 7 \\
\hline 20. & $\begin{array}{l}\text { The same forces which have led to the oppression of Blacks have } \\
\text { also led to the oppression of other groups. }\end{array}$ & 1 & 2 & 3 & 4 & 5 & 6 & 7 \\
\hline
\end{tabular}




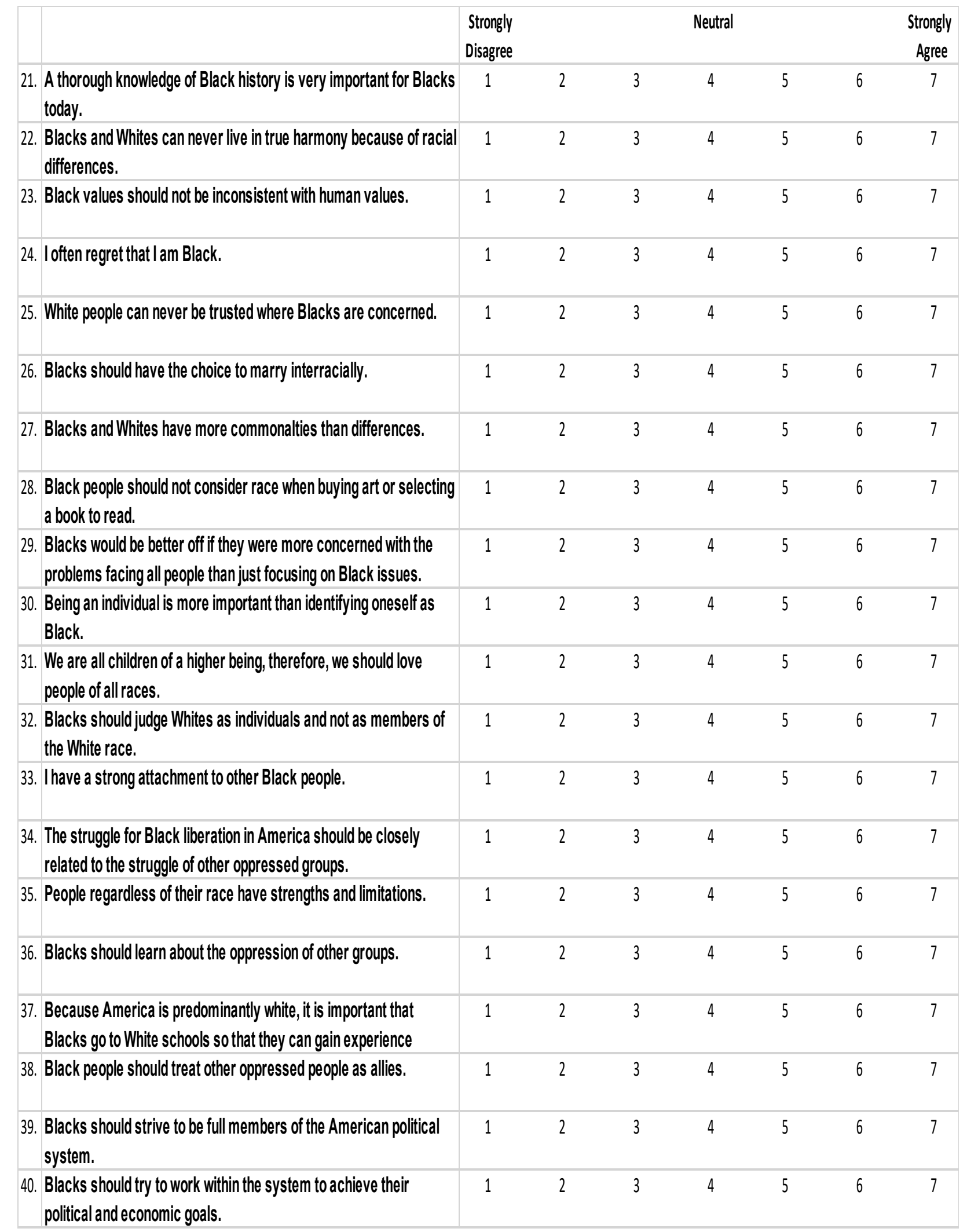




\begin{tabular}{|c|c|c|c|c|c|c|c|}
\hline & $\begin{array}{l}\text { Strongly } \\
\text { Disagree }\end{array}$ & & & Neutral & & & $\begin{array}{l}\text { Strongly } \\
\text { Agree }\end{array}$ \\
\hline $\begin{array}{l}\text { 41. Blacks should strive to integrate all institutions which are } \\
\text { segregated. }\end{array}$ & 1 & 2 & 3 & 4 & 5 & 6 & 7 \\
\hline $\begin{array}{l}\text { 42. The racism Blacks have experienced is similar to that of other } \\
\text { minority groups. }\end{array}$ & 1 & 2 & 3 & 4 & 5 & 6 & 7 \\
\hline 43. Blacks should feel free to interact socially with White people. & 1 & 2 & 3 & 4 & 5 & 6 & 7 \\
\hline $\begin{array}{l}\text { 44. Blacks should view themselves as being Americans first and } \\
\text { foremost. }\end{array}$ & 1 & 2 & 3 & 4 & 5 & 6 & 7 \\
\hline $\begin{array}{l}\text { 45. There are other people who experience racial injustice and } \\
\text { indignities similar to Black Americans. }\end{array}$ & 1 & 2 & 3 & 4 & 5 & 6 & 7 \\
\hline $\begin{array}{l}\text { 46. The plight of Blacks in America will limprove only when Blacks are } \\
\text { in important positions within the system. }\end{array}$ & 1 & 2 & 3 & 4 & 5 & 6 & 7 \\
\hline $\begin{array}{l}\text { 47. Blacks will be more successful in achieving their goals if they form } \\
\text { coalitions with other oppressed groups. }\end{array}$ & 1 & 2 & 3 & 4 & 5 & 6 & 7 \\
\hline 48. Being Black is an important reflection of who lam. & 1 & 2 & 3 & 4 & 5 & 6 & 7 \\
\hline $\begin{array}{l}\text { 49. Blacks should try to become friends with people from other } \\
\text { oppressed groups. }\end{array}$ & 1 & 2 & 3 & 4 & 5 & 6 & 7 \\
\hline 50. The dominant society devalues anything not White male oriented. & 1 & 2 & 3 & 4 & 5 & 6 & 7 \\
\hline 51. Being Black is nota major factor in my social relationships. & 1 & 2 & 3 & 4 & 5 & 6 & 7 \\
\hline 52. Blacks are not respected by the broader society. & 1 & 2 & 3 & 4 & 5 & 6 & 7 \\
\hline 53. In general, other groups view Blacks in a positive manner. & 1 & 2 & 3 & 4 & 5 & 6 & 7 \\
\hline 54. Iam proud to be Black. & 1 & 2 & 3 & 4 & 5 & 6 & 7 \\
\hline $\begin{array}{l}\text { 55. Ifeel that the Black community has made valuable contributions to } \\
\text { this society }\end{array}$ & 1 & 2 & 3 & 4 & 5 & 6 & 7 \\
\hline 56. Society views Black people as an asset. & 1 & 2 & 3 & 4 & 5 & 6 & 7 \\
\hline
\end{tabular}




\section{APPENDIX D}

\section{ID \#}

\section{Demographic and Career Planning Questionnaire}

\section{Gender}

2. Age:

3. In what type of environment where you raised?

_Urban

Suburban

Rural

4. What is the highest education level of your mother?

Unknown

Some High School

High School Graduate

Some College

Associates

Bachelor's

Masters'

Doctorate (MD, PhD)

Law Degree (JD)

5. What is the highest education level of your father?
Unknown
Some High School
High School Graduate
Some College
Associates
Bachelor's
Masters'
Doctorate (MD, PhD)
Law Degree (JD) 
6. What was your family's average income level for the majority of your

childhood (0-18)?
Unknown
Less than $\$ 40,000$
$\$ 40,000-\$ 60,000$
$\$ 60,000-80,000$
$\$ 80,000-\$ 100,000$
Greater than $\$ 100,000$

7. What is your academic year?

Freshman

Sophomore

Junior

Senior

Graduate

Other

8. Have you declared a major?

Yes No

If yes, please list your major(s):

If not, please list majors you are considering:

$1^{\text {st }}$ choice:

$2^{\text {nd }}$ choice:

9. Which race/ethnicity do you identify with? (You may select more than one)
African-American/Black
Asian-American/Asian
Hawaiian/Pacific Islander
European-American/white
Hispanic-American/Latino
Native American

Other:

10. What is the highest degree you expect to receive?

High School Diploma/GED only 
Bachelor's Degree (4-year BA/BS)

Master's Degree (MA/MS)

Law Degree (JD)

Medical Degree (e.g., MD, DDS, DVM)

Doctorate (e.g., Ph.D., Ed.D)

Other:

List five occupations you have considered in thinking about your future. List both ones you have dreamed about as well as those you have discussed with others.
Appeal
Occupation

- Now arrange each in terms of its appeal to you today (i.e., place a "1" in front of the one that has the most appeal, $a$ " 2 " in front of the one with the next most appeal, and so forth).

- Put a circle around the choices that others (e.g., parents, spouse, best friend, relative, teacher) think you should do.

- Put an "I" in front of any that seem impossible because of requirements (e.g., educational, financial, personal).

- Put an " $F$ " in front of any that represent "fantasy" choices (i.e., fun but not realistic in your opinion).

- Put an " $\mathrm{H}$ " in front of any that might quality more as what you would pursue as a hobby or avocation. 


\section{Informed Consent Statement}

This study examines your perceptions of your preparedness and your outlook on your future career plans. You will be asked to complete a series of questionnaires addressing how you feel about engaging in career preparatory tasks, your career outlook, confidence in making career decisions, confidence in performing academic tasks, and your feeling that you belong in the college environment.

Your participation in this study is voluntary and you may withdraw at any time. The time required to participate in this study will be approximately 45 minutes. If you complete all of the requirements of this study, you will be entered into a raffle to receive 1 of $40 \$ 25$ Best Buy gift cards.

If you have any questions about the materials, as the individual overseeing the completion of the study for clarification please contact Jason Edwards, the primary investigator for this study. He may be contacted by email at jle8c4@mail.missouri.edu. Please contact him if any further questions arise about the study being conducted or your participation in the study.

Principal Investigator: Jason Edwards, MA

University of Missouri

Department of Educational, School, and Counseling Psychology

Email: jle8c4@mail.missouri.edu

Patrick Rottinghaus, Ph.D.

Department of Educational, School and Counseling Psychology

rottinghausp@missouri.edu

This project has been reviewed and approved by the University of Missouri--Columbia Institution Review Board (IRB: 2010497).

"I have read the above information and agree to participate in the study described above. I have received a copy of this informed consent form and understand that participation is voluntary and that I may withdraw at any time"

Signature:

Date: 


\section{VITA}

Jason Edwards was raised in St. Louis Missouri where he graduated from Lutheran High School North. He then earned his B.A from Washington University in St. Louis with majors in psychology and African American Studies. Following his undergraduate studies, Jason worked in Information Technology for several organizations before going to graduate school to earn a MA in Counseling Psychology from Boston College and an MBA from the University of Michigan. Jason worked for two financial firms in New York city as an equity research analyst. After his graduate studies, Jason began his work as a mental health therapist working with both children and adults at Jewish Family \& Children's service, a community mental health agency in St. Louis, MO. After gaining experience as clinician, he began his doctoral studies at the University of Missouri where he worked under the guidance of Patrick Rottinghaus.

As doctoral student, Jason trained at trained at the University of Missouri's counseling center as a clinical graduate assistant for three years. He also taught multicultural classes to undergraduate students in the College of Education. Jason completed his clinical internship at the counseling center at Emory University in Atlanta, GA. Most recently, he was a psychology resident at the University of Missouri counseling center while also completing his doctoral dissertation. He will graduate with his $\mathrm{PhD}$ in counseling psychology in August of 2021. Jason intends to continue applying his clinical skills at the University of Missouri's Counseling Center. 